\title{
Moscow Test Well, INEL Oversight Program: Aqueous Geochemistry
}

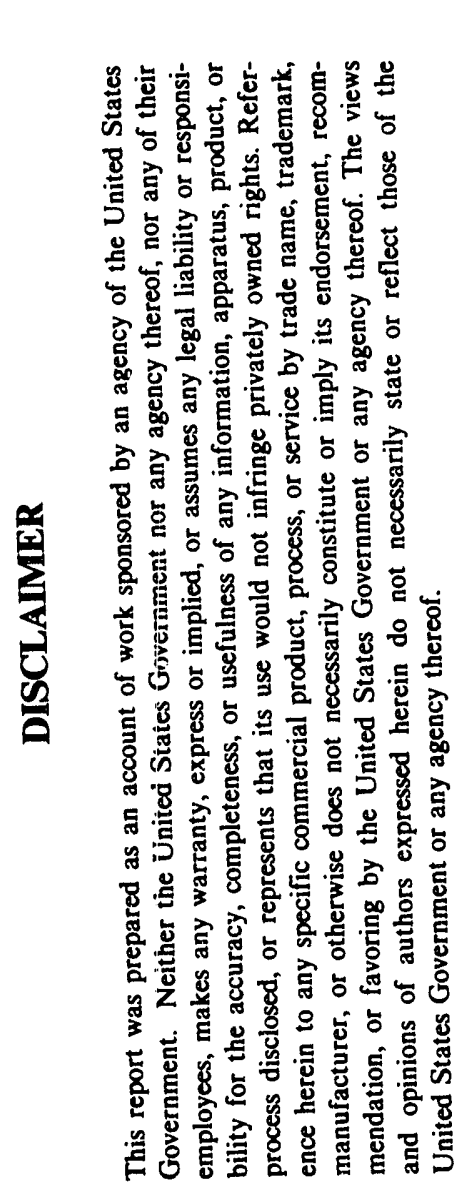

\author{
by \\ Michael McCurry and Jeanne Fromm \\ Idaho State University \\ , John Welhan \\ Idaho Geological Survey
}

September 29, 1992

Technical Report 
TOPICS

Page

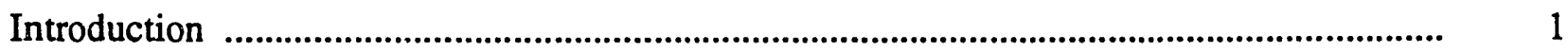

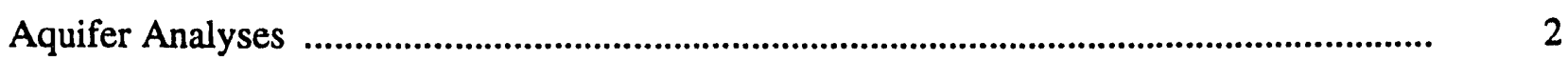

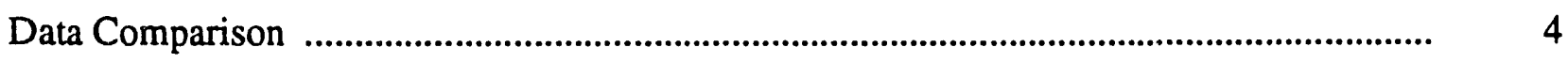

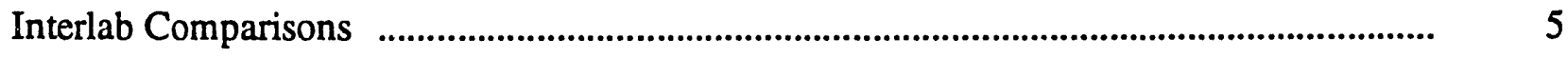

Blanks and Spikes

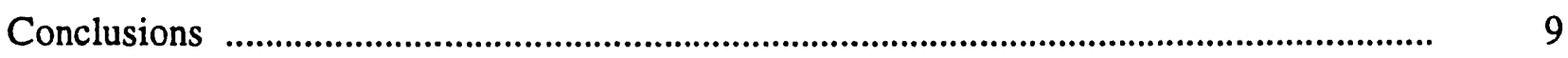

Appendix: Tabulation of geochemical data from Moscow Test Well ............................... 12

\section{FIGURES}

Fig. 1 Sketch Map of Moscow Test Site .............................................................. 1

Fig. 2 Comparison of Moscow Test Well with nearby well ......................................... 2

Fig. 3 Comparison of bailer and packer samples .......................................................... 4

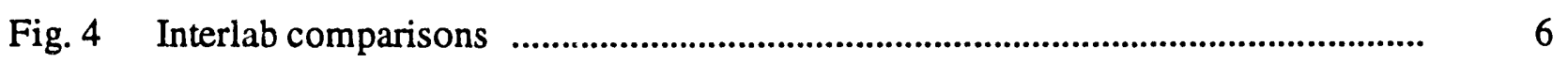

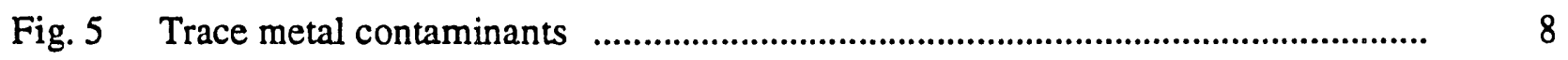

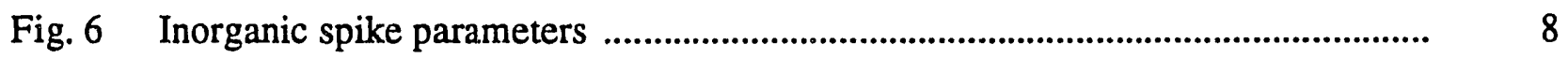

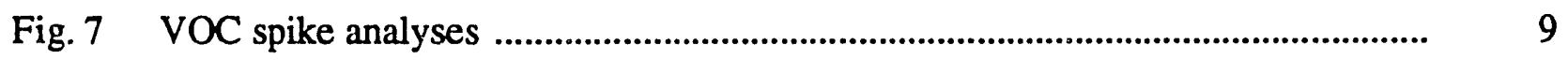

\section{TABLES}

Table 1 Summary of geochemical data from Moscow Test Well .................................... 3

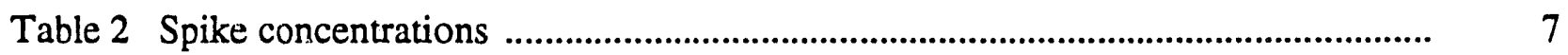




\title{
Moscow Test Well, INEL Oversight Program: Aqueous Geochemistry
}

\author{
by, Michael McCurry and Jeanne Fromm, Idaho State University \\ John Welhan, Idaho Geological Survey

\section{INTRODUCTION}

This report presents a summary and interpretation of data gathered during sampling of the Moscow Test Well at Moscow, Idaho during April and May of 1992 . The principal objectives of this chemical survey were to validate sampling procedures with a new straddle packer sampling tool in a previously hydrologically well characterized and simple sampling environment, and to compare analytical results from two independent labs for reproducibility of analytical results. Analytes included a wide range of metals, anions, nutrients, BNA's, and VOC's.

Secondary objectives included analyzing of waters from a large distilled water tank (utilized for all field laboratory purposes as "pure" stock water), of water which passed through a steamer used to clean the packer, and of rinsates from the packer tool itself before it was lowered into the test well. Analyses were also obtained of blanks and spikes for data validation purposes.

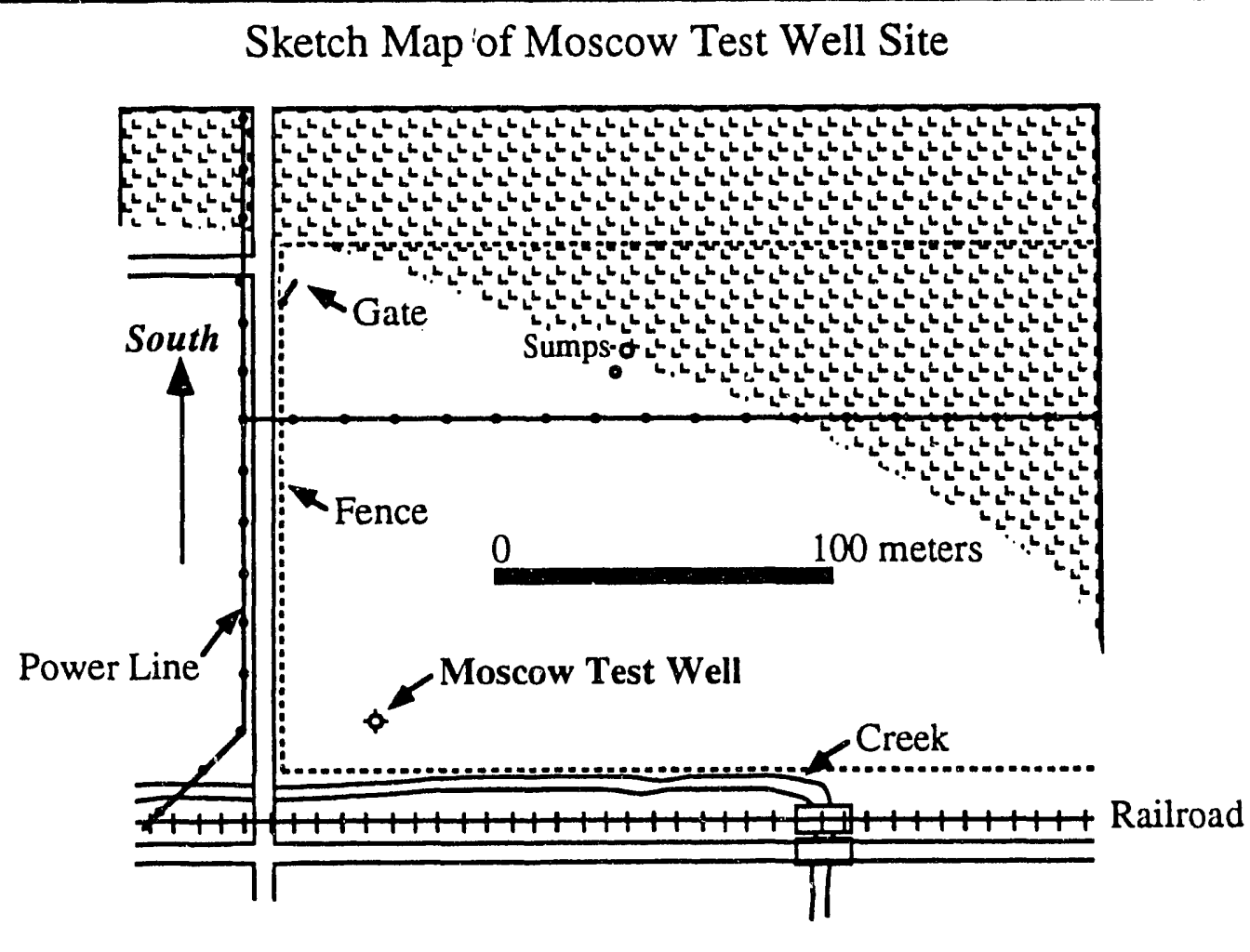

Figure 1. Sketch map of the Moscow Test Well site, Moscow, Idaho. The site is located on pasture land on the northwest comer of the University of Idaho. 
A complete listing of analytical results and related data validation information are given in Appendix I. A summary of these data are presented in Table 1.

\section{Aquifer Analyses}

Aquifer analyses were obtained first using a bailer to sample at $75^{\prime}$ depth, then with the packer tool. The packer was configured to sample at the same depth, with the lower packer inflated, and the upper packer not inflated. The upper packer was not inflated because of mechanical problems.

Summaries of analyses are listed in Table 1. Twenty-two analytes and 26 of 40 inorganic parameters were at or above detection limit. No organic compounds (VOC's or BNA's) were detected. All of the analytes yielded values in the range we expected based upon the general character of the aquifer.

No previous analytical data from this well were available for comparison. An analysis of water from a well located about 100 ESE of the test well yielded values which differ significantly from those obtained in this study (Figure 2). The Moscow Test Well samples vary from one-third to three times the values from the comparison well. However, they are of the same order of magnitude, and we believe the differences are primarily due to the complicated nature of the aquifer rather than rather than anything to do with our sampling procedures.

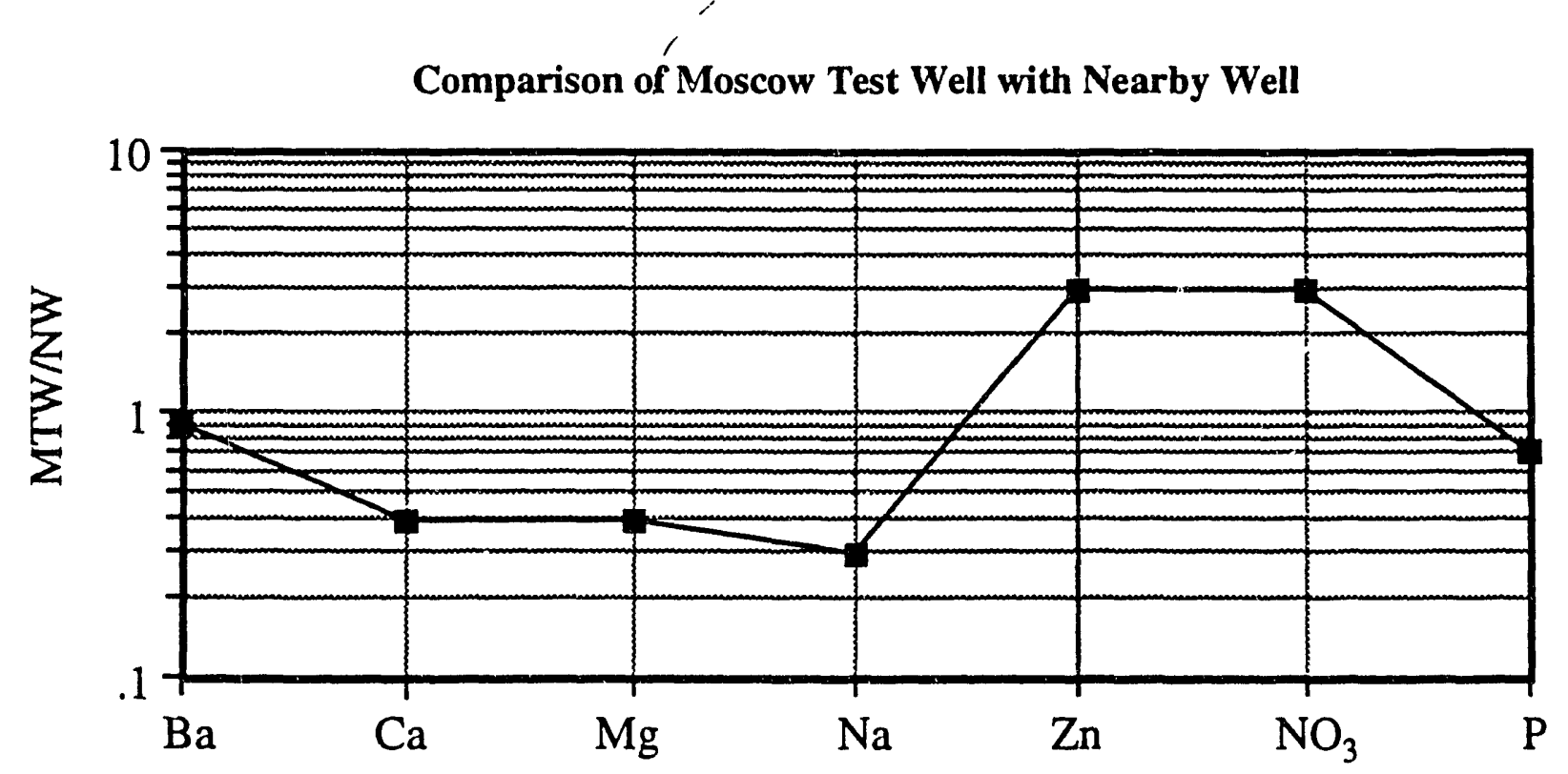

Figure 2. Analyses of ground water from the Moscow Test Well are compared to those of an unnamed well located approximately $100 \mathrm{~m}$ east-southeast; means of bailer and packer derived samples are divided by analyses from the nearby well values. Analyses from the nearby well were obtained from J. Kauffman, Univ. of Idaho (personal communication, 1992). 


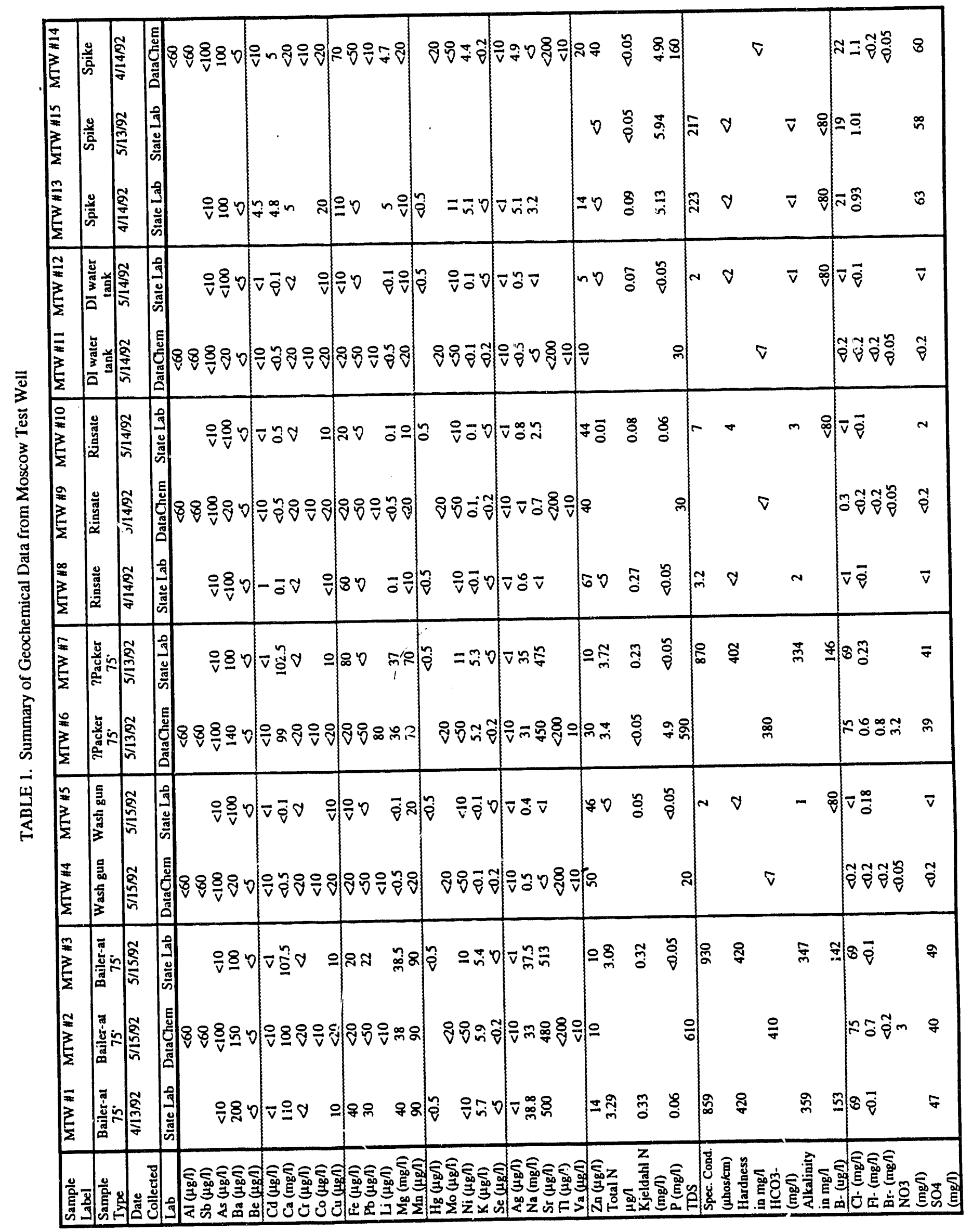




\section{Data Comparison}

Packer and bailer analyses are compared in Figure 3. Averages of bailer samples analyses (where at above detection limit levels) are divided by similarly averaged packer samples. Therefore, samples plotting in the top half of the diagram (i.e. with values more than 1) are enriched in bailer samples, those with values less than one are enriched in packer samples. With a few prominent exceptions, packer and bailer samples either correlate to within analytical uncertainties, or are consistent with each other (at values below recorded detection limits).

Seven analytes yielded differences well outside the range which could be expected from sampling and analytical uncertainties (Figure 2). The most prominent of these are $\mathrm{Pb}, \mathrm{Li}, \mathrm{N}$ and $\mathrm{Br}$. These differ by factors of three to eight $(\mathrm{Li})$.

\section{Comparison of Bailer and Packer Samples}

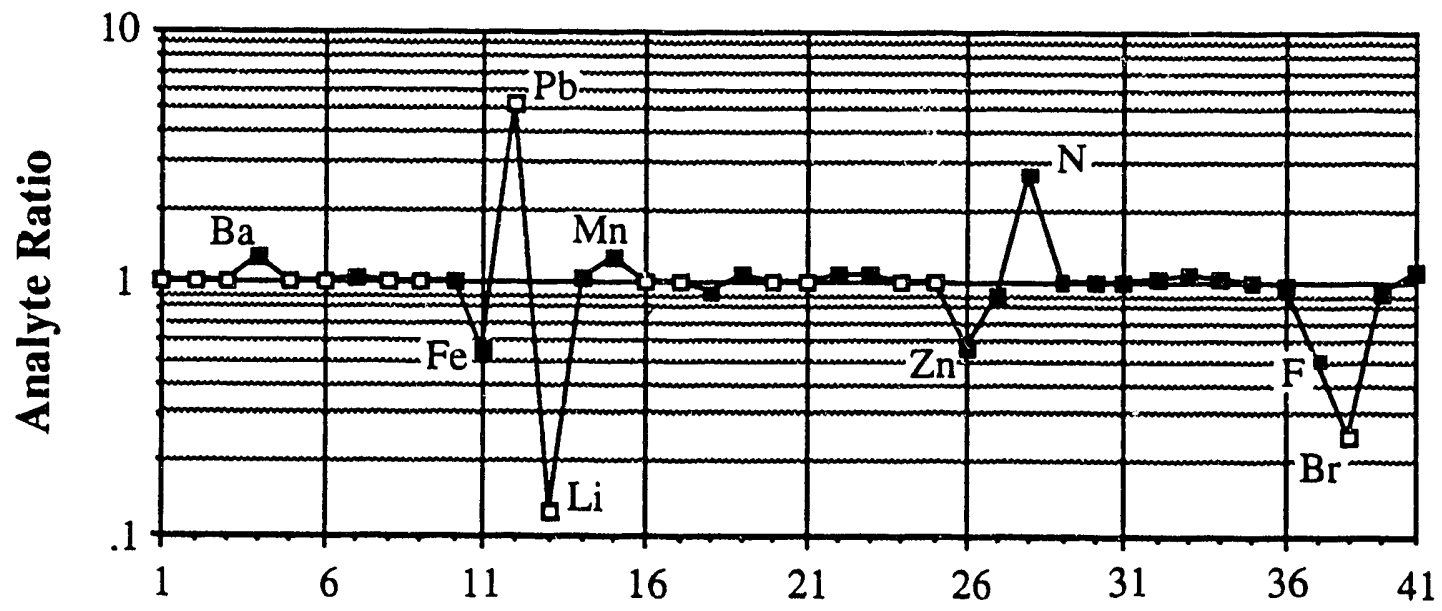

Figure 3. Analyte concentrations from bailer samples are divided by the respective concentrations for packer samples for comparision purposes. Analytes are listed by number, in the same order as they are listed in Table 1 , beginning with $\mathrm{Al}$ (analyte 1). Open squares are for cases in which one analyte is below detection limit; therefore these are limiting values. Analytes which yielded concentration differences beyond what was expected for sampling and analysis uncertainties are highlighted by name.

Variations among most of the metals exhibit a pattern of enrichments and depletion's (defined as bailer/packer concentration) which are difficult to account for. $\mathrm{Pb}$, and to a lesser extent $\mathrm{Ba}$ and $\mathrm{Mn}$ show enrichment, whereas Fe, $\mathrm{Li}$ and $\mathrm{Zn}$ exhibit depletion's. Analyses of blanks, spikes, and stock DI water would seem to rule out gross analytical error or preparation procedures as the cause of the differences. Three possibilities are suggested. First, that the differences result from real variations in aquifer chemistry. Second, that they result from an unknown source of contamination. Third, subtle analytical errors resulting from measurements made near detection limits. 
Lithium, Bromide and Kjeldahl nitrogen anomalies may be better explained. Lithium and bromide are both below detection limits for bailer derived samples and occur at concentrations of 80 and $800 \mu \mathrm{g} /$ in packer samples. On a molar basis the concentrations of $\mathrm{Li}$ and $\mathrm{Br}$ are 11.5 and $10.1 \mu \mathrm{mol} /$; these concentrations are probably identical to within analytical uncertainties. The fact that both lithium and bromide are present in packer samples, and do not occur in any other samples, indicates that these elements were incompletely removed by purging after introduction of the $\mathrm{LiBr}$ tracer into the "packed" interval.

It is also possible that these differences are natural variations in the aquifer system. However, the fact that they are present in the samples in stoichoimetrically balanced proportions with respect to the tracer makes such an origin unlikely.

Incomplete $\mathrm{LiBr}$ tracer removal may be a significant problem in future sampling proceedures. This is particularly important for measurements which may reach the sub-ppb range (i.e. by ICP-MS), as trace metal contaminants from the tracer may occur at measureable levels. It is therefore recommended to obtain lot analyses of the $\mathrm{LiBr}$ tracer for metals of interest.

Finally, Kjeldahl nitrogen is significantly higher in bailer than packer samples. We believe this is probably because of contamination of the bailer from waters shallow in the well.

\section{Interlab comparisons}

Two independent labs produced data for a variety of metals and anions using different analytical techniques. For example, the State Lab and DataChem analyzed for metals respectively using Furnace AA and ICP techniques. Analytical results are compared in Figure 4. For common analytes most of the lab results compare favorably, generally to within analytical uncertainties.

Possible exceptions may include F, Sr and $\mathrm{Zn}$. $\mathrm{Zn}$ and $\mathrm{F}$ concentration ratios (State Lab divided by DataChem values) are significantly low for packer samples, and $\mathrm{Sr}$ is high for a rinsate sample. However, their is no consistent pattern of enrichment or depletion. Both labs yielded similar results for bailer and packer samples for $\mathrm{Sr}$ and $\mathrm{Zn}$. Similarly; F spike values are within $10 \%$ of each other for both labs and of the actual prepared value, indicating good precision and accuracy. We have no adequate explanation for the three observed excursions, and therefore recommend that future work includes sending of a subset of samples to both labs to evaluate whether this is a recurring problem. 


\section{Interlab Comparisons}

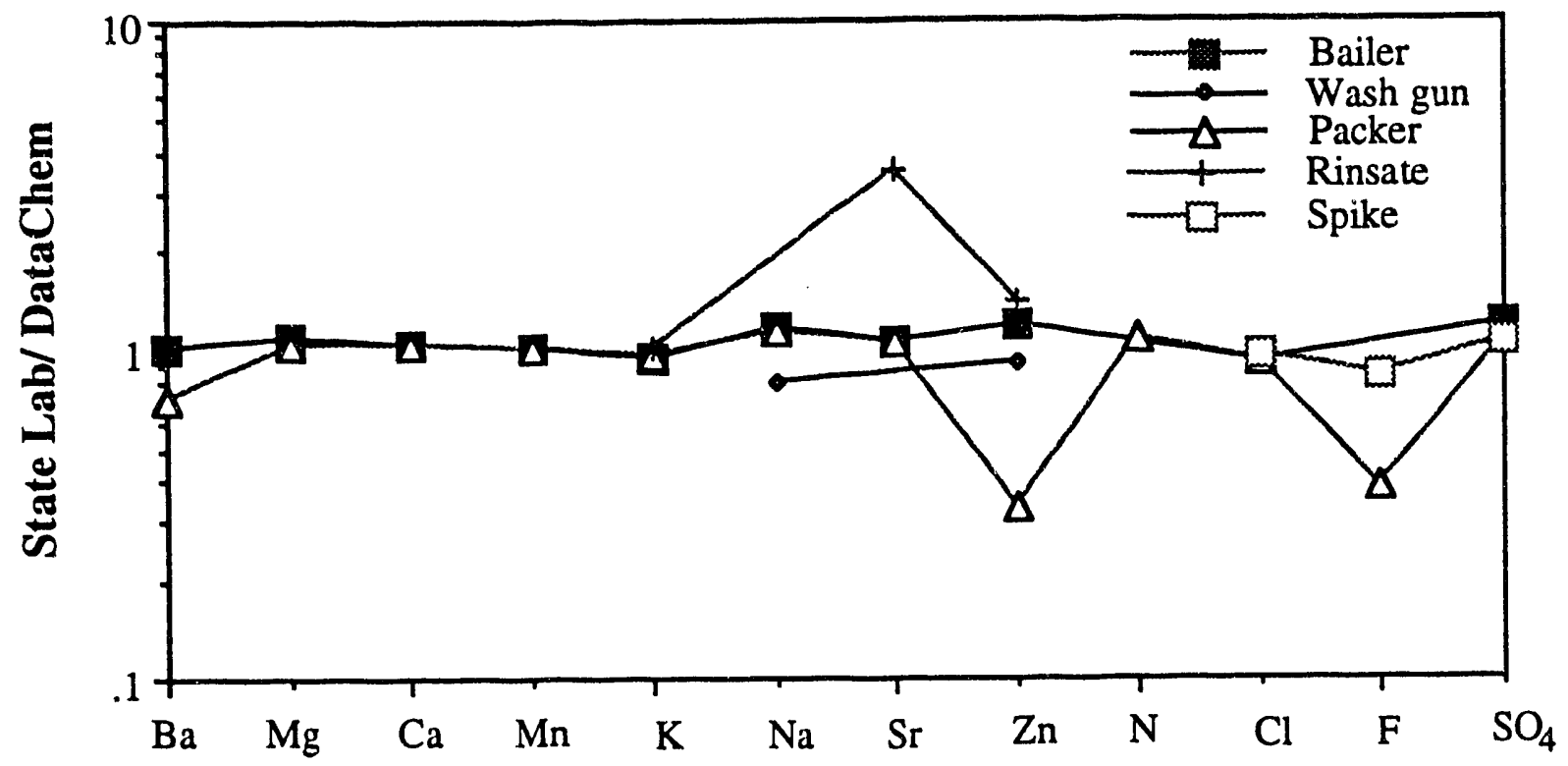

Figure 4. A comparison of analyte values for the Idaho State Lab and for DataChem. Comparisons are shown for analytes for which the State Lab and DataChem received duplicate samples and which yielded concentrations above detection limits for the respective labs.

\section{Blanks and Spikes}

Several blank and spiked samples were analyzed along with other samples. Composite summaries of the analyses are listed in Table 1. Complete data on these samples is listed in Appendix I.

There are two types of blank samples. One set, for metals, anions, and nutrients, was prepared in the field using stock distilled water, and adding preservatives, in a manner identical to the other samples. The second, for VOC's and BNA's, was prepared in Boise at the Bureau of Laboratories, Idaho Department of Health and Welfare. They were mailed to the field station at Moscow, Idaho, during operations. They were then relabeled in the normal course of work at the well site and returned to Boise as unknowns along with other samples.

Spiked solutions were prepared in Boise at the Bureau of Laboratories, Idaho Department of Health and Welfare. They were mailed to the field station at Moscow, Idaho, during operations. They were then relabeled in the normal course of work at the well site and returned to the respective labs as unknowns along with other samples. Spike concentrations are listed in Table 2. 
TABLE 2. Spike Concentrations ${ }^{a}$

\begin{tabular}{|c|c|c|c|c|c|c|c|c|c|c|c|c|}
\hline $\begin{array}{c}\text { Metals - } \\
\mu \mathrm{g} / 1\end{array}$ & $\begin{array}{c}\mathrm{Ba} \\
100\end{array}$ & $\begin{array}{c}\mathrm{Ca} \\
5,000\end{array}$ & $\begin{array}{c}\mathrm{Cd} \\
5\end{array}$ & $\begin{array}{c}\mathrm{Cr} \\
5\end{array}$ & $\begin{array}{l}\mathrm{Cu} \\
20\end{array}$ & $\begin{array}{l}\mathrm{Fe} \\
100\end{array}$ & $\underset{5,000}{K}$ & $\begin{array}{c}\mathrm{Mg} \\
5,000\end{array}$ & $\begin{array}{c}\mathrm{Na} \\
5,000\end{array}$ & $\begin{array}{l}\mathrm{Ni} \\
10\end{array}$ & $\begin{array}{c}\mathrm{Pb} \\
5\end{array}$ & $\begin{array}{l}\mathrm{Zn} \\
10\end{array}$ \\
\hline $\begin{array}{c}\text { Anions - } \\
\mathrm{mg} / 1\end{array}$ & $\begin{array}{l}\mathrm{Cl} \\
20\end{array}$ & $\begin{array}{c}\mathrm{Fl} \\
1\end{array}$ & & & & & & & & & & \\
\hline $\begin{array}{l}\text { Nutrients - } \\
\mathrm{mg} / \mathrm{l}\end{array}$ & $\mathrm{NO}_{3}$ & & & & & & & & & & & \\
\hline
\end{tabular}

VOC's - Regulated VOC's listed in Table 2: $5 \mu \mathrm{g} / \mathrm{l}^{\mathrm{b}} \quad$ Tetrachlorethene: $5 \mu \mathrm{g} / \mathrm{l}^{\mathrm{b}}$

BNA's - $\quad$ All BNA's listed in Table 2: $5 \mu \mathrm{g} / 1$

a. Spike solutions prepared at the Bureau of Laboratories, Idaho Dept. of Health and Welfare; they were mailed to the field at Moscow, Idaho, during operations. They were then relabeled in the course of this project and returned to the State Lab and to DataChem Lab as unknowns along with other samples.

b. One spike solution, labeled MTW\#16 in Table 1, was spiked with $20 \mu \mathrm{g} /$ of the respective VOC analytes (W. Baker, personal communication, 1992).

Inorganic blanks samples are listed in Table 1 as DI water tank samples, samples MTW\#11 and 12, sent respectively to the DataChem and the State Lab. All parameters register at below detection limits, except for $\mathrm{K}, \mathrm{Na}, \mathrm{Zn}, \mathrm{P}$, and Kjeldahl $\mathrm{N}$. All are at low coricentrations, but are well above detection limits. It seems clear that the stock deionized water tank contained minor but significant levels of contamination by these elements.

Additional samples were taken from the steam sprayer, used to clean the packer before insertion into the well. Little additional contamination seems to have occurred in water which passed through the cleaner with the exception of $\mathrm{Zn}$. Concentrations of several metals are compared from the DI reservoir, spray gun and rinsate from the packer to compare and contrast various sources of contamination (Figure 5). Note that zinc increases by a factor of 10 from the DI stock to spray gun. No other significant variation was noted. We have no direct evidence of where $\mathrm{Zn}$ may have entered the water, however on possibility is that the water came in contact with solder within the water heater.

The packer itself is obviously contaminated with a variety of substances. Fortunately, with the possible exception of $\mathrm{Na}$, all appear to be at low concentration levels, and were presumably removed from the packer during the cleaning process.

Spiked samples analyses from the State Lab compare favorably with prepared concentrations for all but two inorganic analytes (Figure 6). All analytes are within analytical uncertainties excepting SO4 and possibly $\mathrm{Zn}$, 


\section{Trace Metal Contaminants}

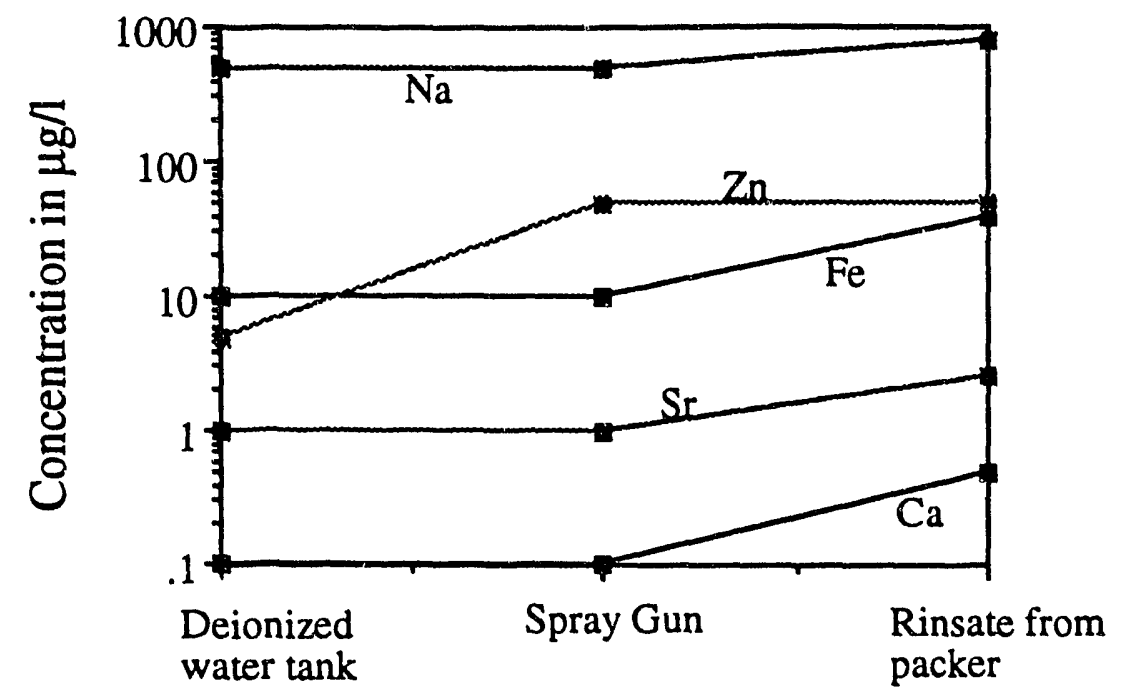

Figure 5. Selected trace element contents from solutions sampled from the main deionized water tank, from the spray gun used to steam clean the packer, and from water which drained ofi the packer during the steam cleaning process.

which are low by $70 \%$ and $30 \%$, respectively. These results are very good given that the complex nature of the spiked solutions may have given rise to sample instability (J. Dodd, personal communication, 1992). The low sulfate is a concern, and particular attention should be directed at the analyte in future work to determine if it is consistently low.

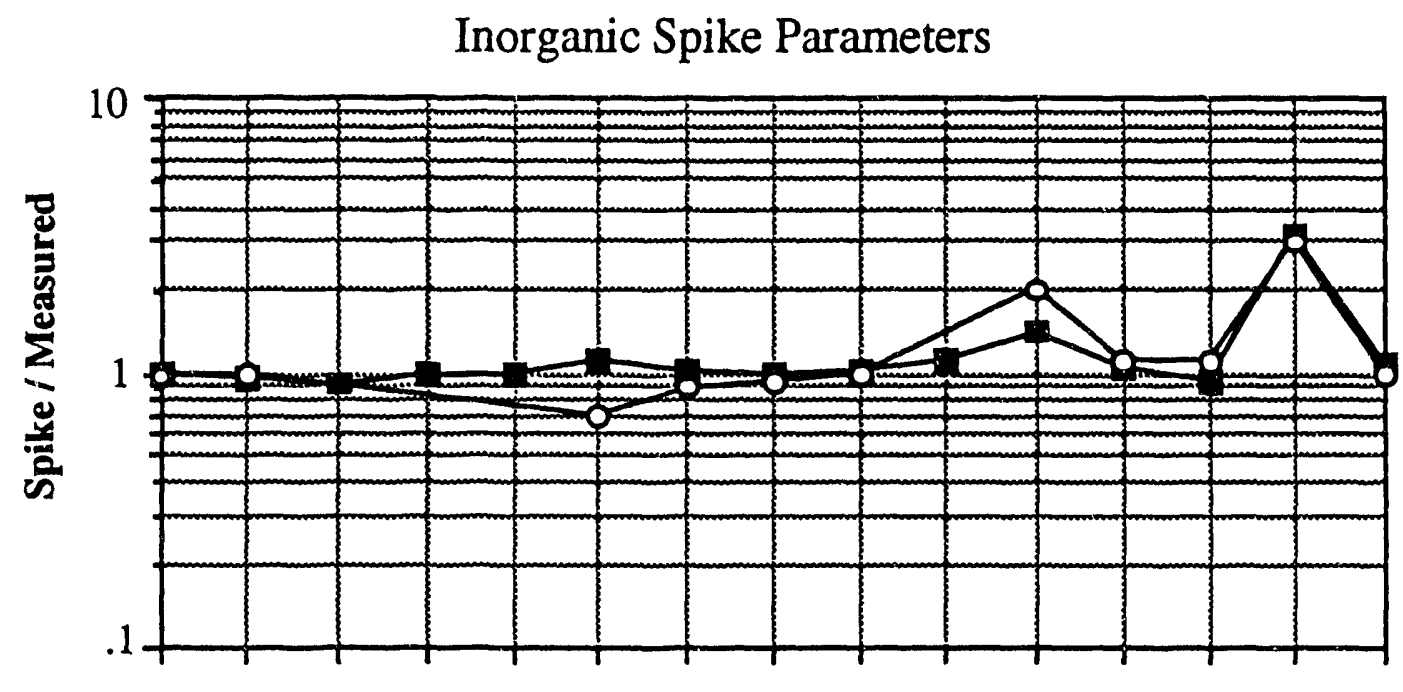

$\begin{array}{lllllllllllllll}\mathrm{Ba} & \mathrm{Ca} & \mathrm{Cd} & \mathrm{Cr} & \mathrm{Cu} & \mathrm{Fe} & \mathrm{K} & \mathrm{Mg} & \mathrm{Na} & \mathrm{Ni} & \mathrm{Zn} & \mathrm{Cl} & \mathrm{F} & \mathrm{SO}_{4} & \mathrm{P}\end{array}$

Figure 6. Prepared spike concentrations are divided by measured values for a variety of inorganic analytes. Only those analytes registering at above detection limits are shown. State Lab - closed squares; DataChem - open circles. 
VOC spikes also yielded acceptable analyses. Analyzed values are compared to the prepared concentrations in Figure 6. Considerable scatter occurs in one set of analyses. This spike was prepared with spike concentrations of $5 \mathrm{ppb}$; the other was prepared with $20 \mathrm{ppb}$ spike concentrations (W. Baker, personal communication, 1992). The apparently random scatter at the lower concentration suggests that the State's system is working at near detection limits at the $5 \mathrm{ppb}$ level.

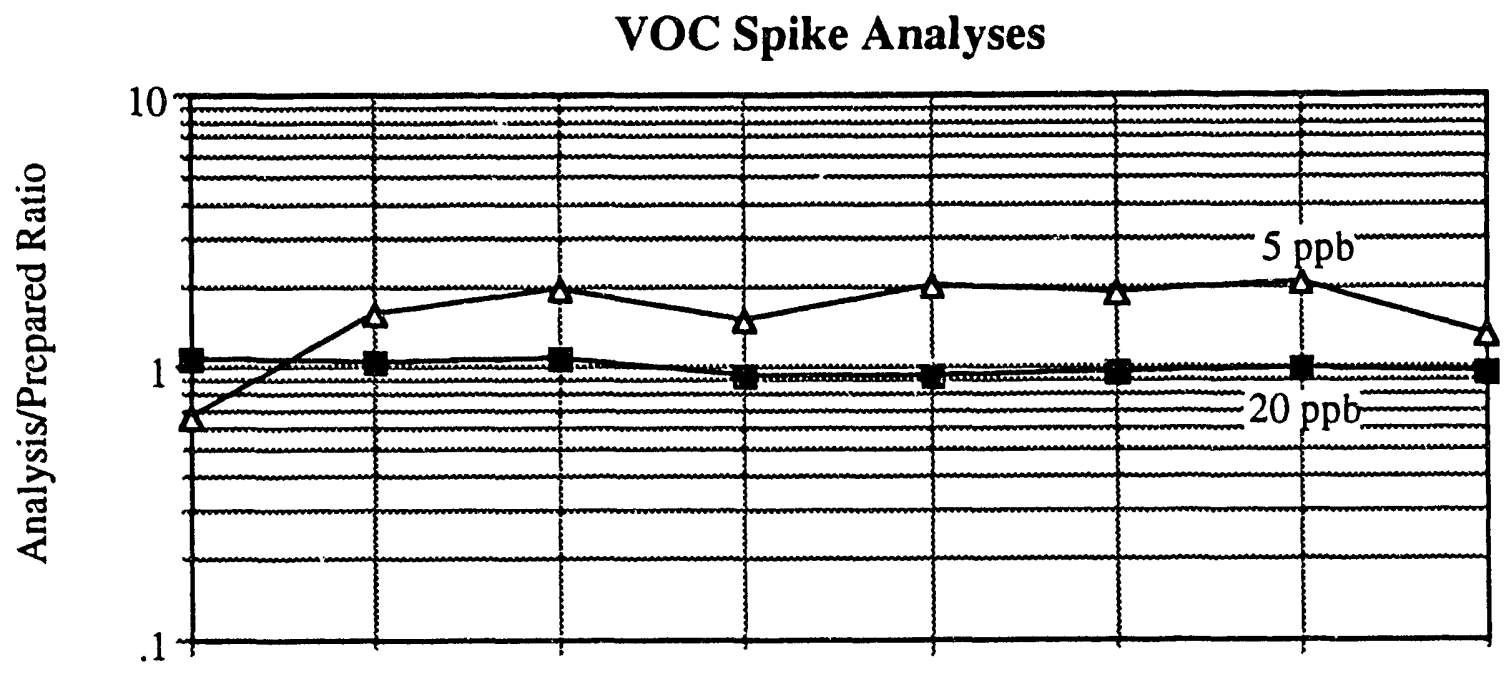

Figure 7. Prepared spike concentrátions are divided by measured values for eight regulated VOC's listed in Appendix I. Two types of spikes were analyzed, one at $5 \mu \mathrm{g} / \mathrm{ml}$ (shown as $\mathrm{ppb})$, the other at $20 \mu \mathrm{g} / \mathrm{ml}$.

No BNA spikes yielded analyses registering at above detection limits (Appendix I lists the analytes). The apparent absence of BNA's probably resulted from laboratory problems, which have since been corrected (W. Baker, personal communication, 1992).

\section{Conclusions}

Results of the Moscow Test are generally satisfactory. However, several significant problems were identified. First, several analytes yielded discordant results $\left(\mathrm{Sr}, \mathrm{Zn}, \mathrm{F}\right.$, and possibly $\left.\mathrm{SO}_{4}\right)$. We therefore recommend that at least a subset of samples be analysed at an independent lab, using different analytical methods where possible. Second, significant deviations were identified between bailer and packer which could not be adequately accounted for $(\mathrm{Fe}, \mathrm{Pb}, \mathrm{Zn})$. Additional work should be done to identify the source of variation among these analytes: for example, to determine whether sporadic sources of contamination or analytical problems may be involved. Thirdly, the steam cleaner appears to be a significant source of $\mathrm{Zn}$ contamination. It may not be possible to completely eliminate this source of contamination, but it should be considered in future interpretations of $\mathrm{Zn}$ data. Fourth, BNA determinations from the State Lab are below specifications. 
The problem has been identified, and corrective measures taken. However, this should be verified in future work with additional spikes. Finally, significant amounts of $\mathrm{LiBr}$ tracer remain in the well water under the sampling conditions employed in this pilot study. The amounts are large enough to exceed natural water concentrations of both $\mathrm{Li}$ and $\mathrm{Br}$. Residual tracer could present a problem for other analytes if methods with detection limits to picograms per liter (e.g., ICP-MS) are used. Since we hope to do this in the future, we should obtain lot analyses for relevant constituents from the $\mathrm{LiBr}$ stock. 
APPENDIX 1. Tabulation of geochemical data from Moscow Test Well. 


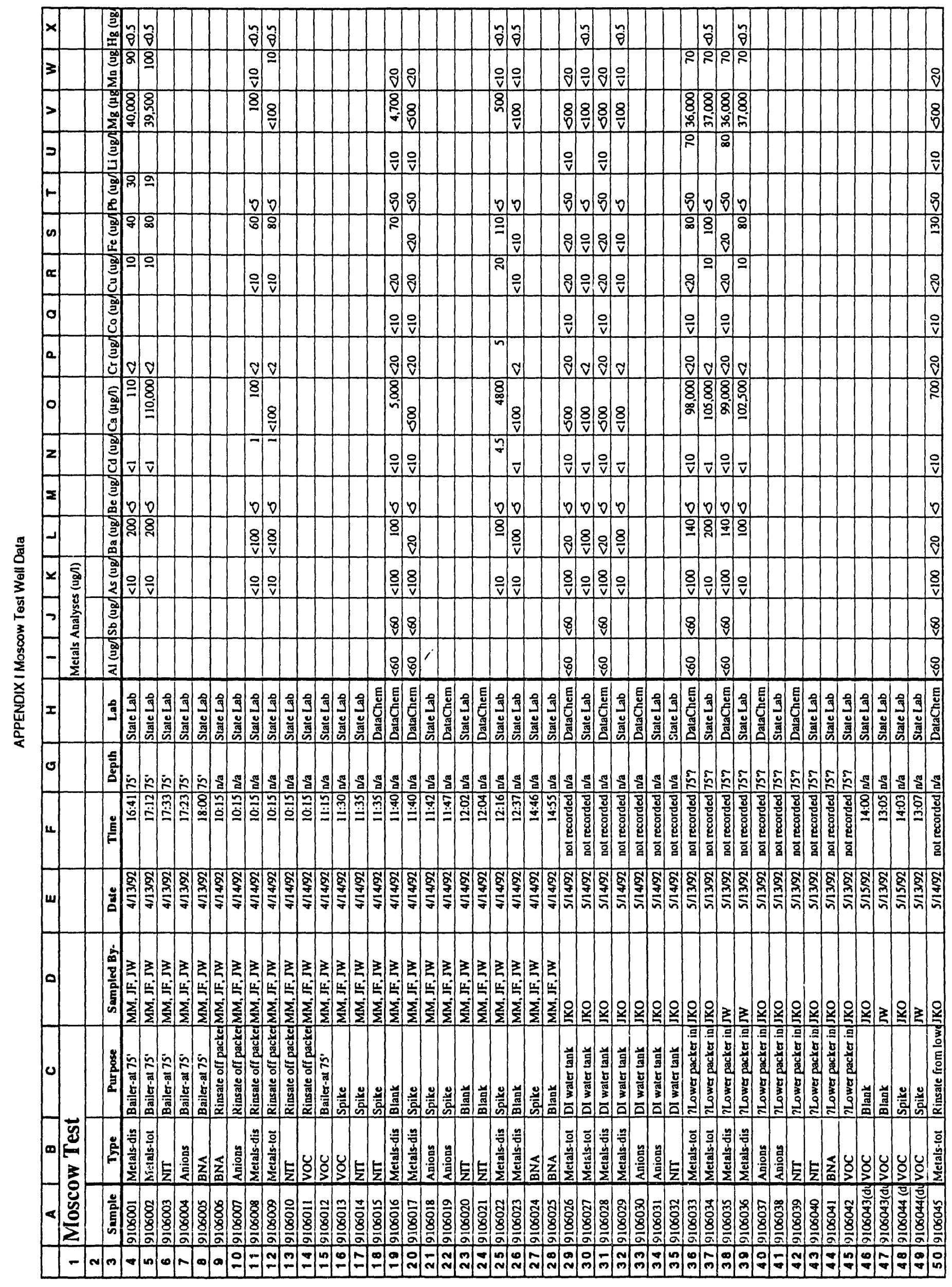




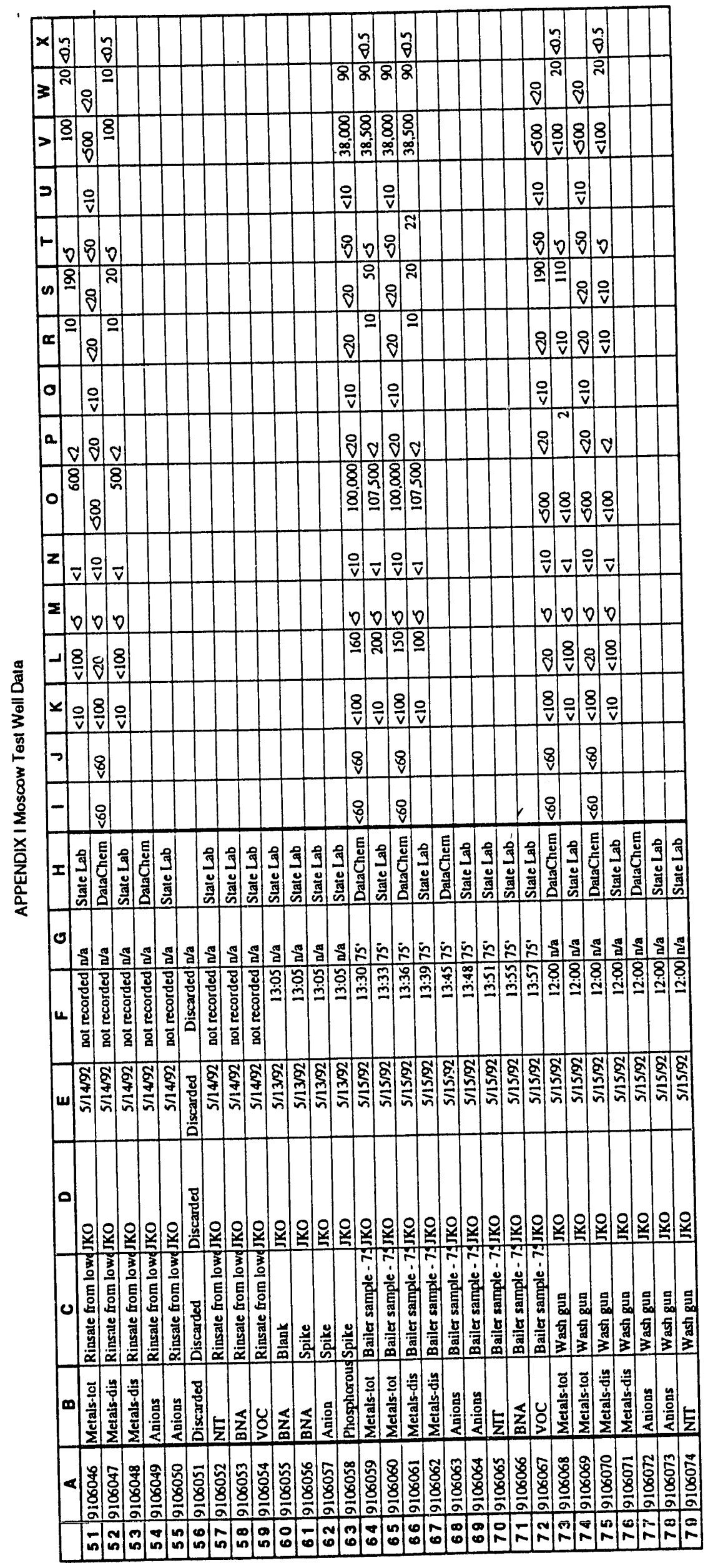




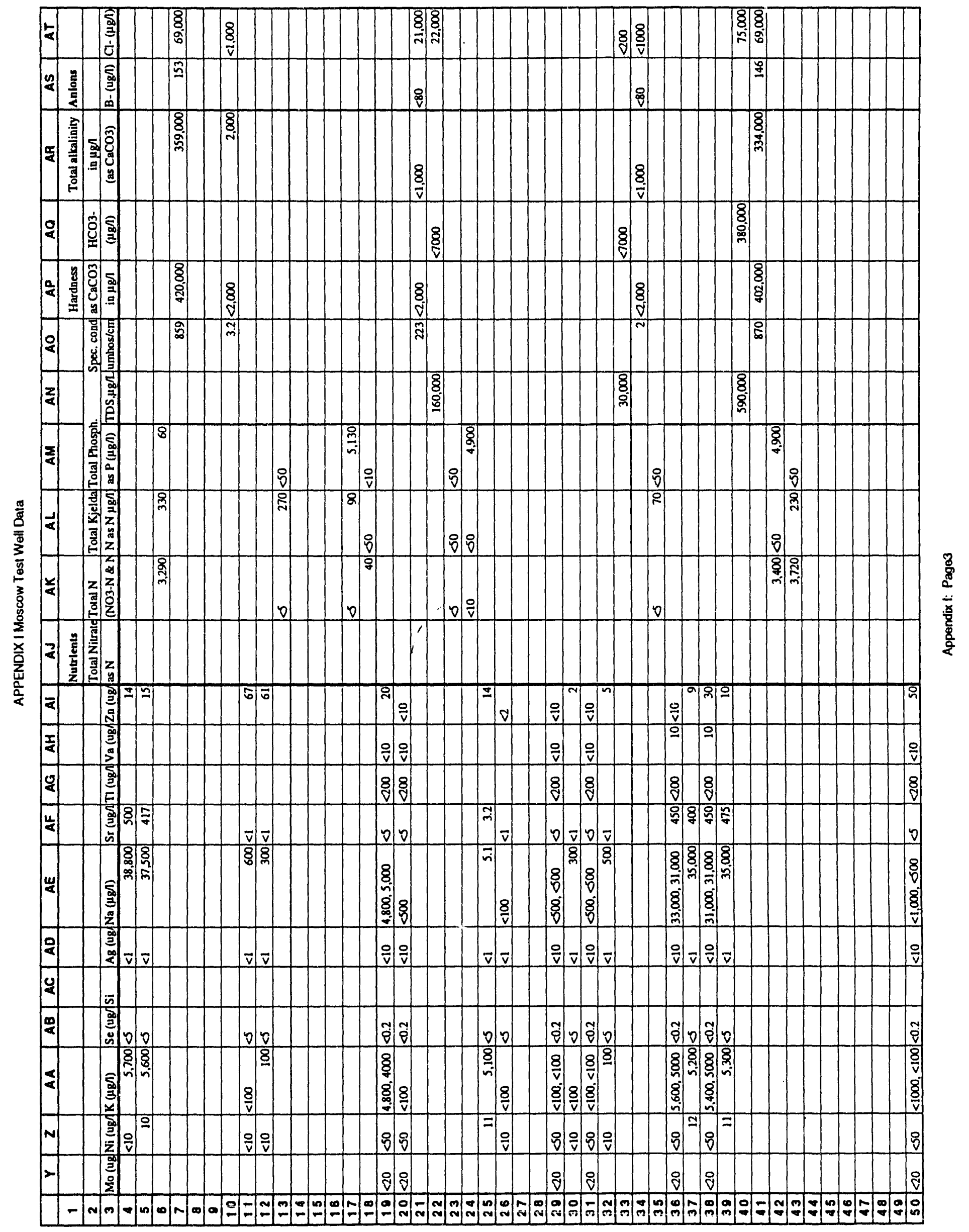




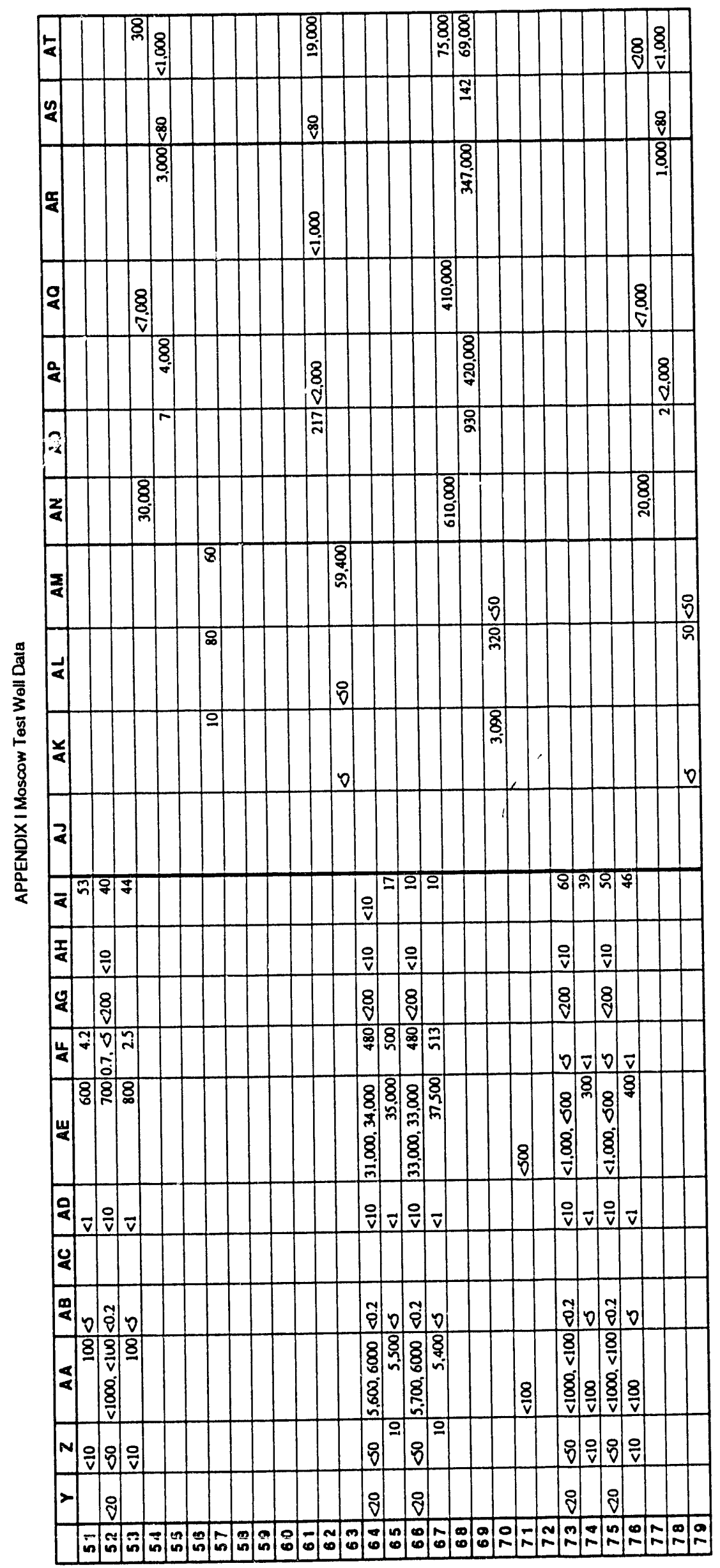

1 


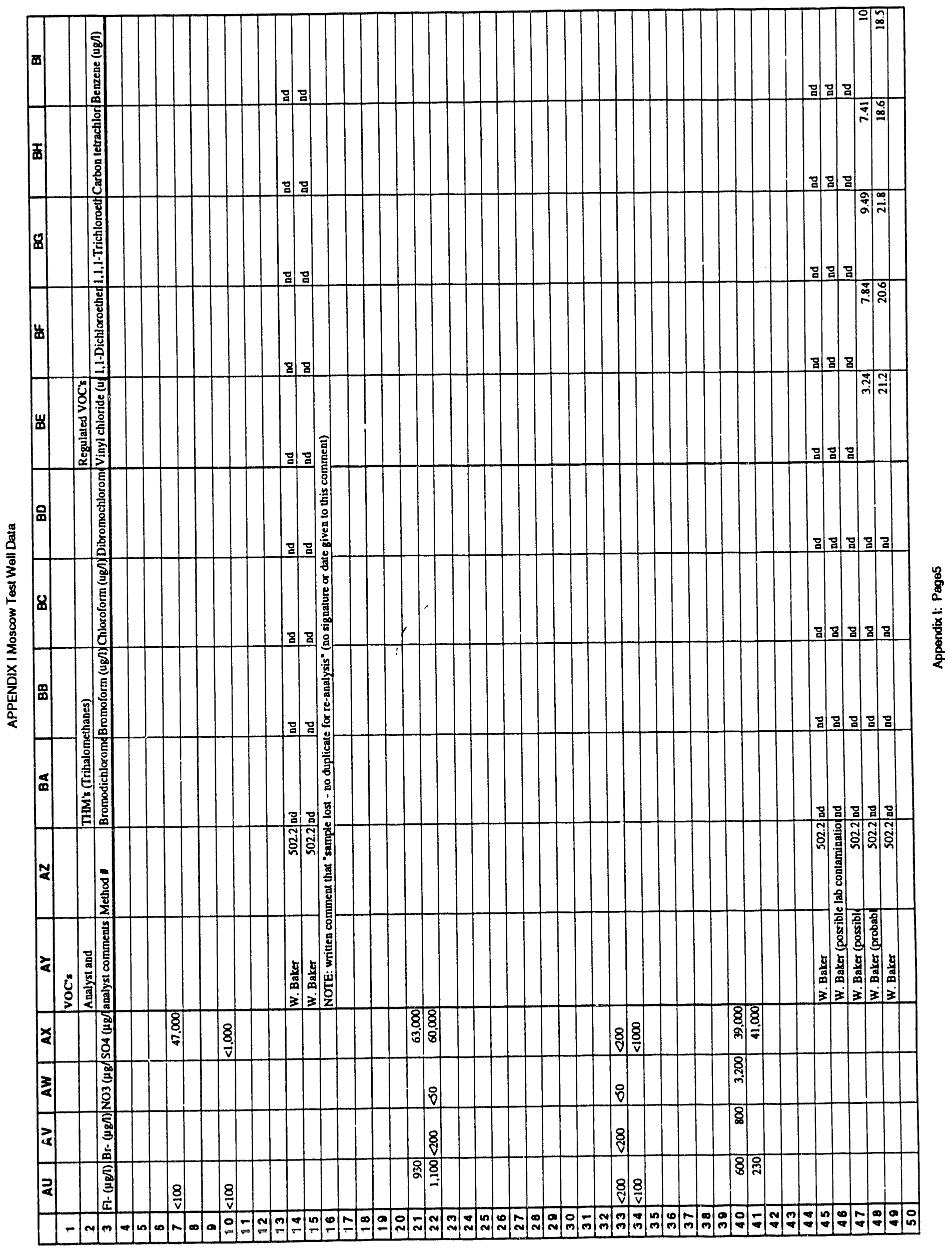




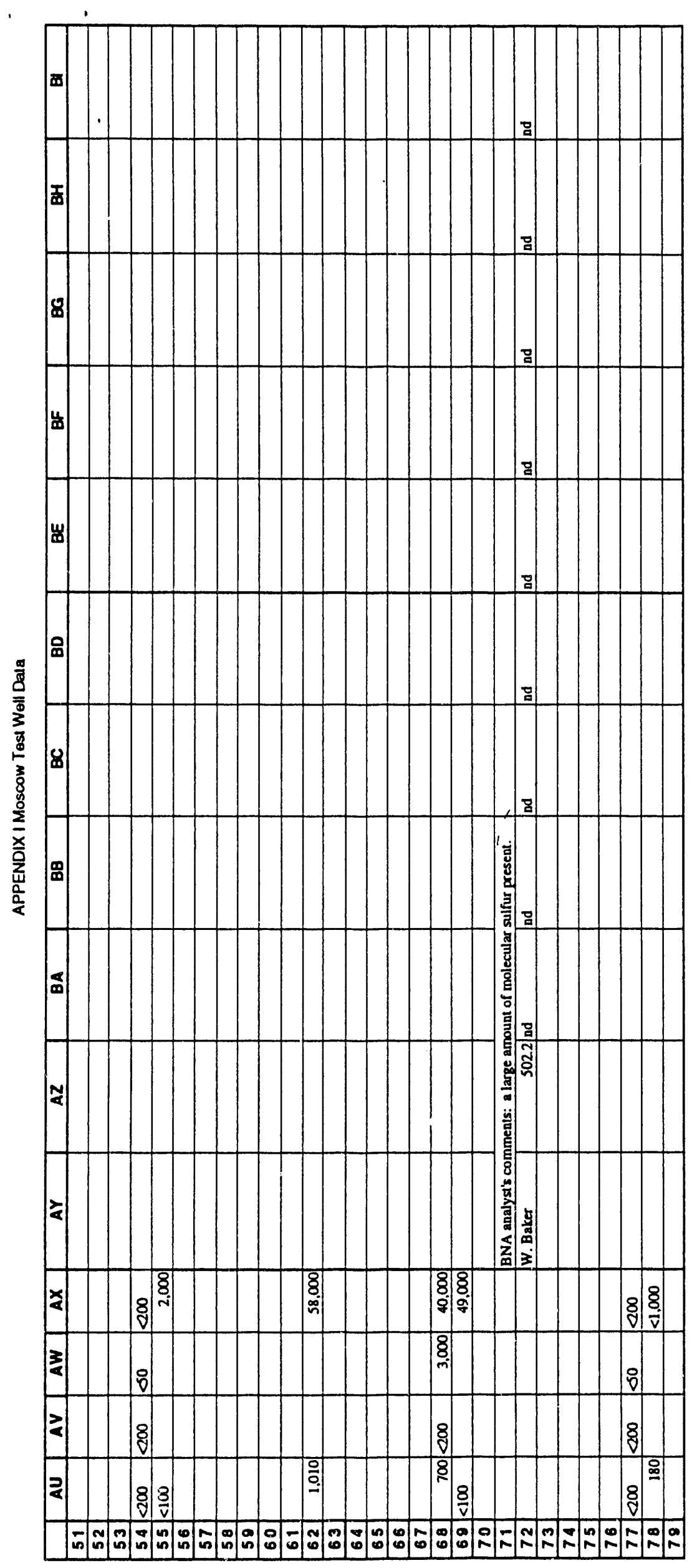

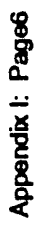




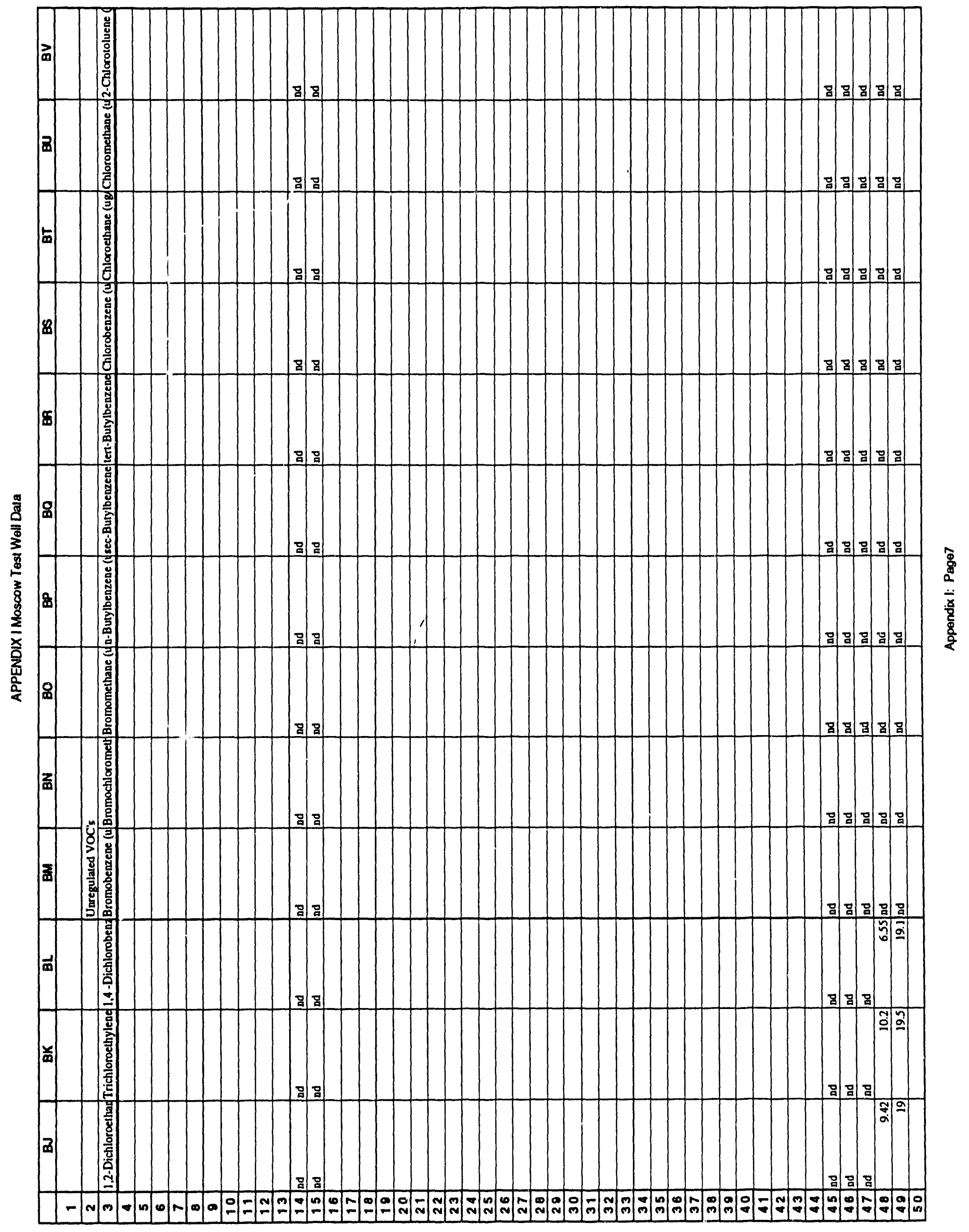




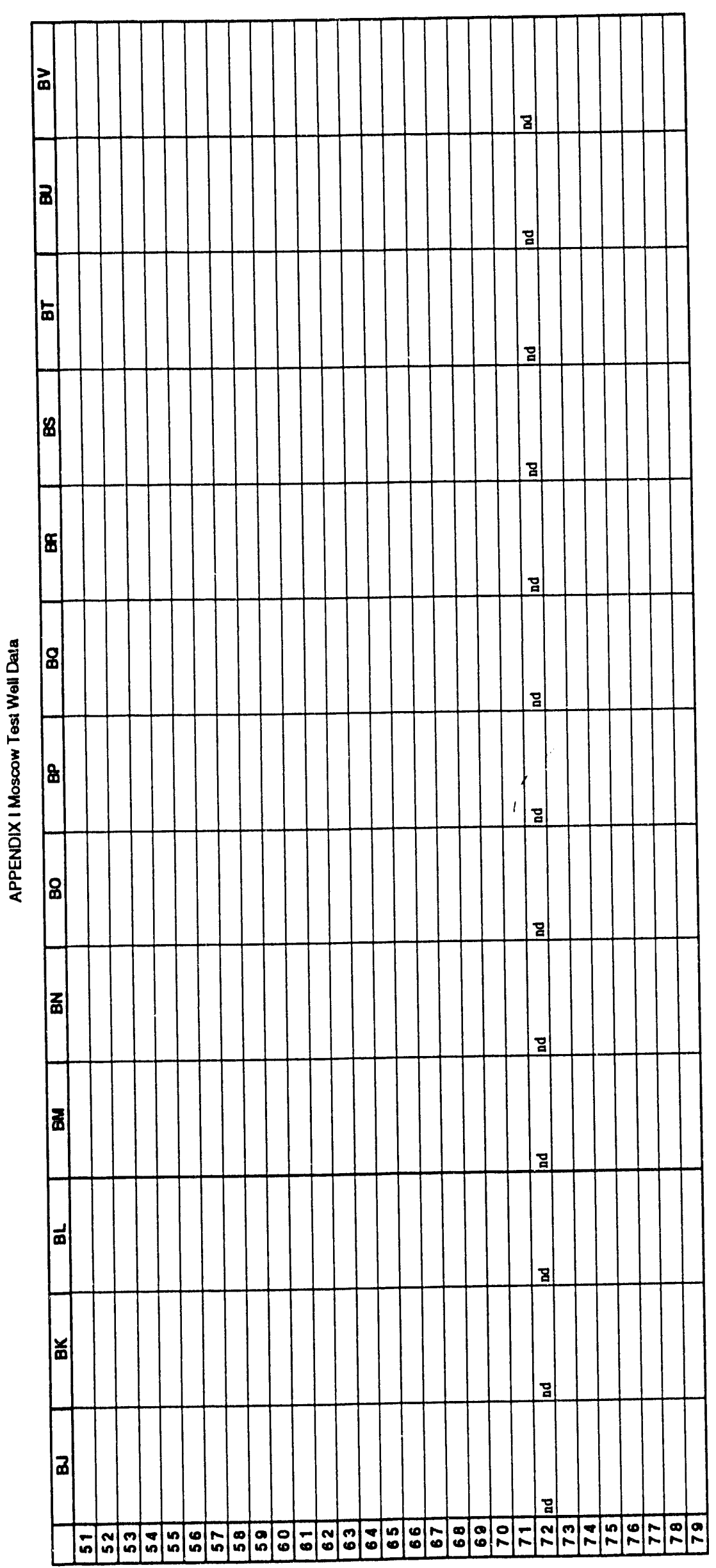

$\frac{8}{8}$
$\frac{8}{2}$
$\frac{-}{7}$
$\frac{8}{6}$
$\frac{8}{2}$ 


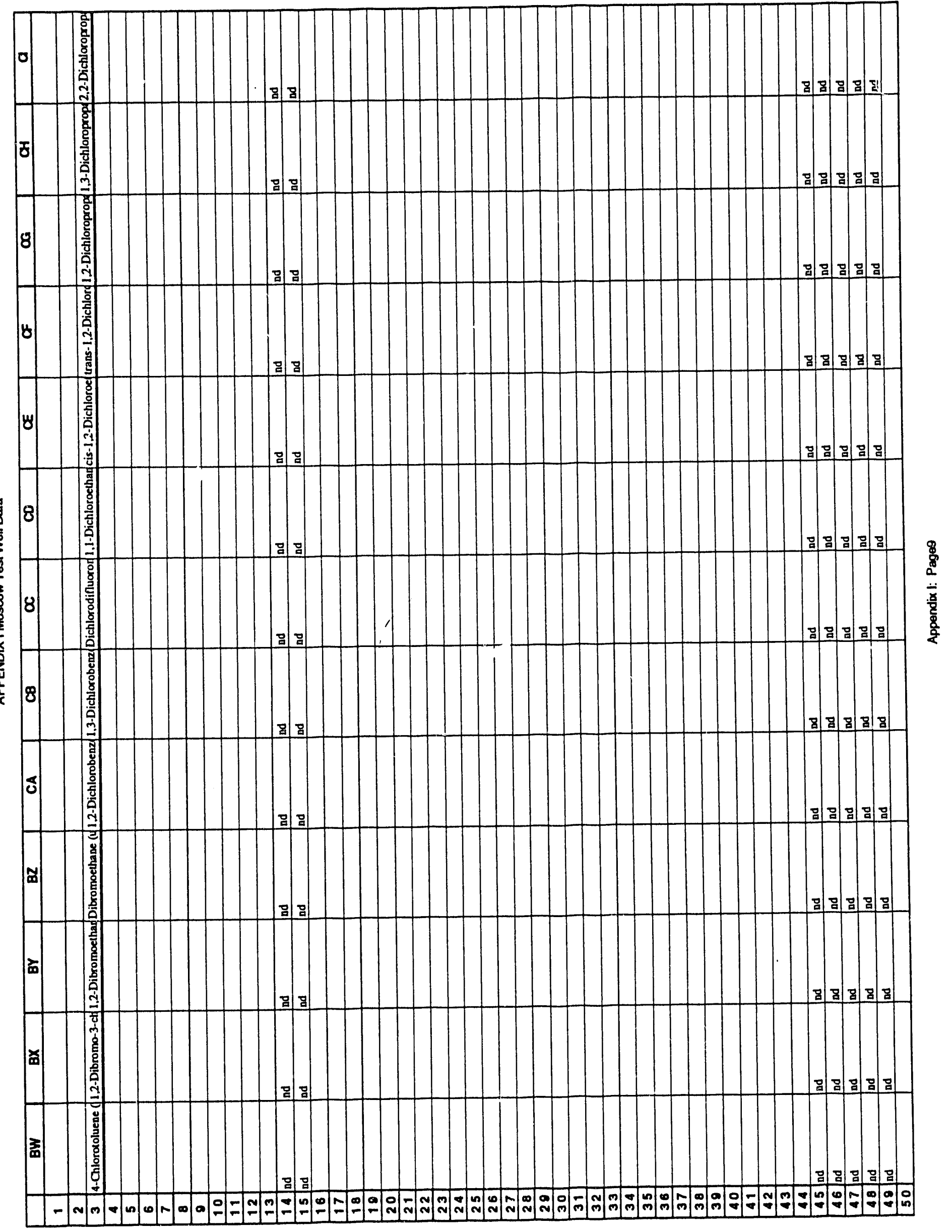


0

छ

.

8

:

$y$

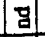

$y$

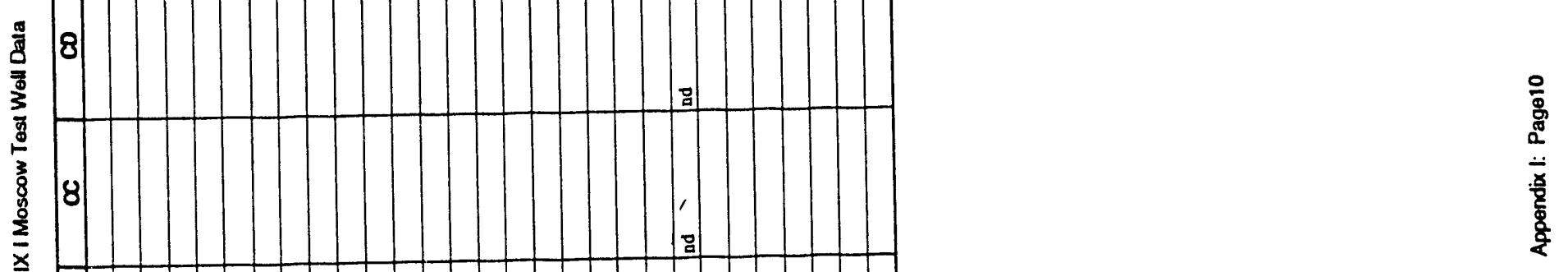

ฮิ

๗

囟

뚜

8

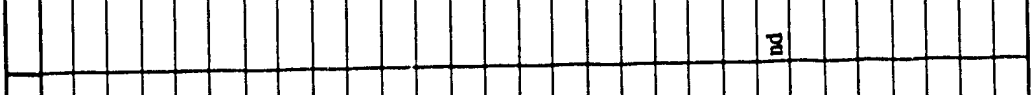

离

맘

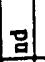

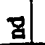

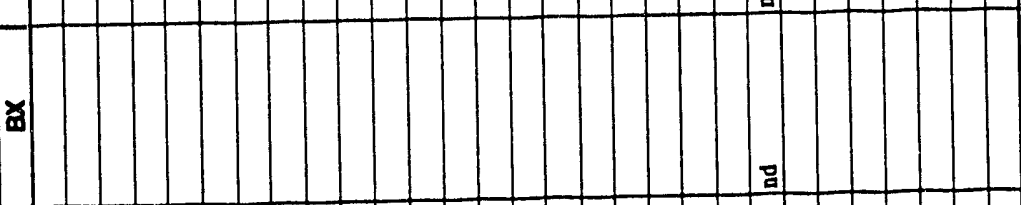

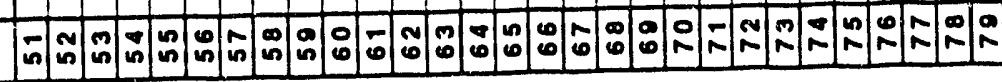




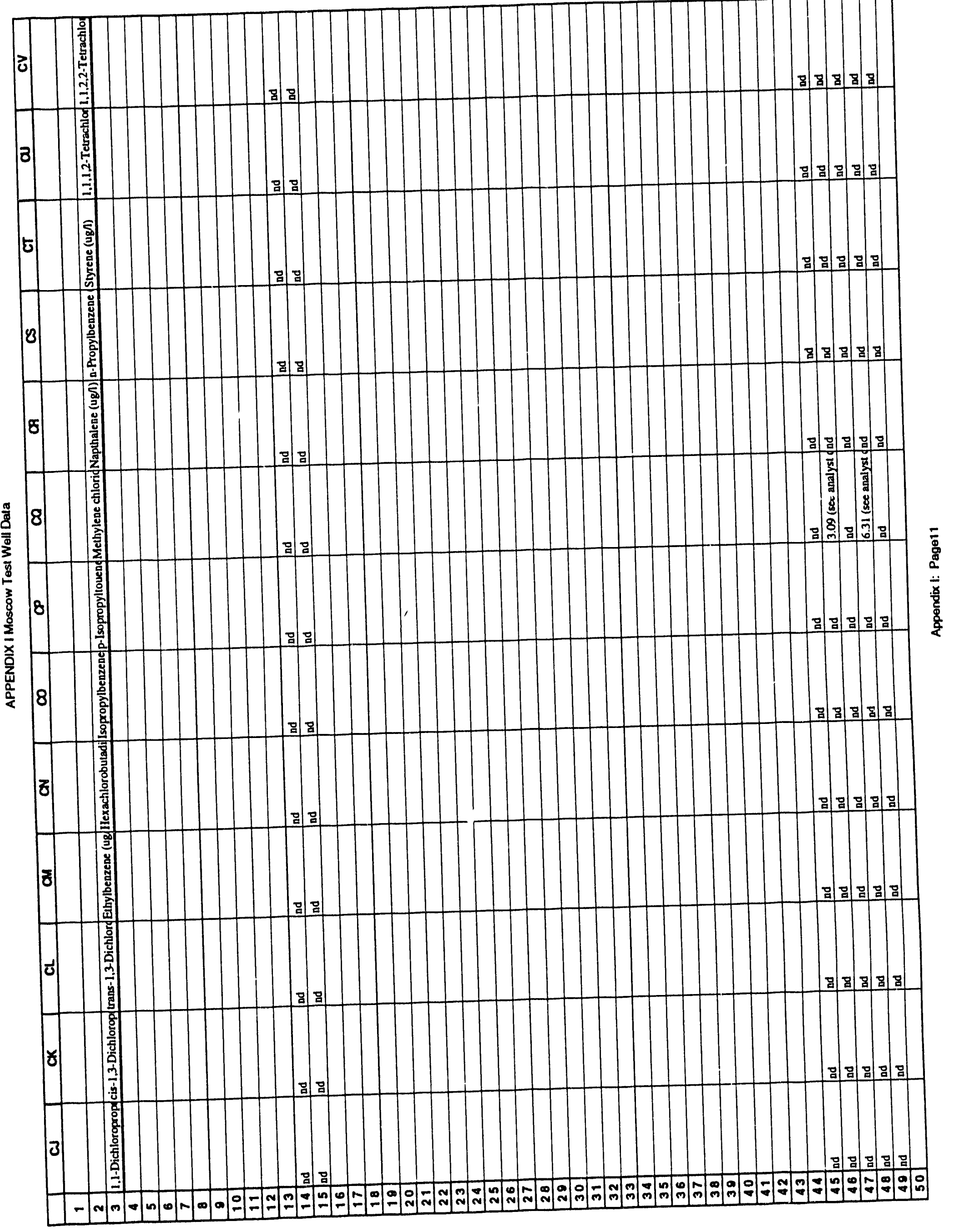




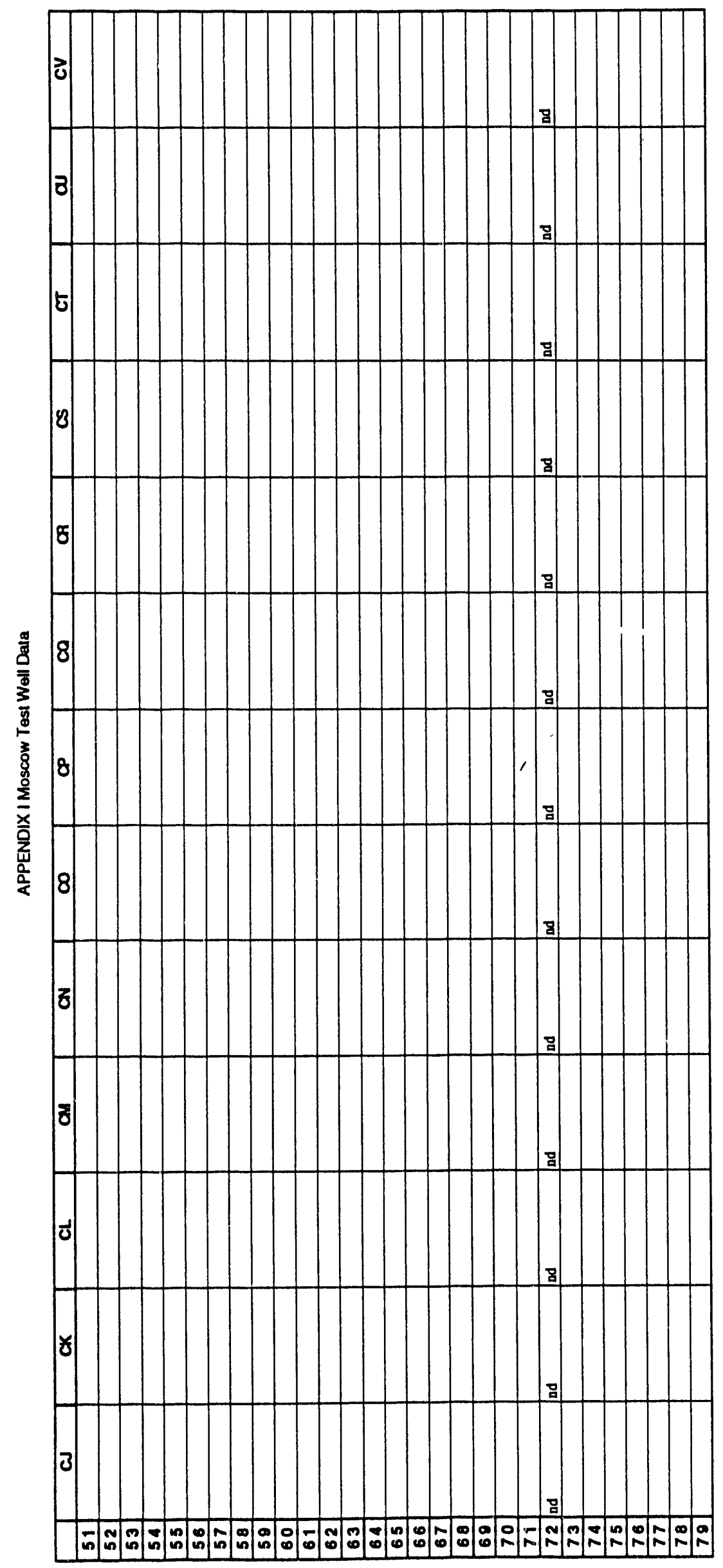




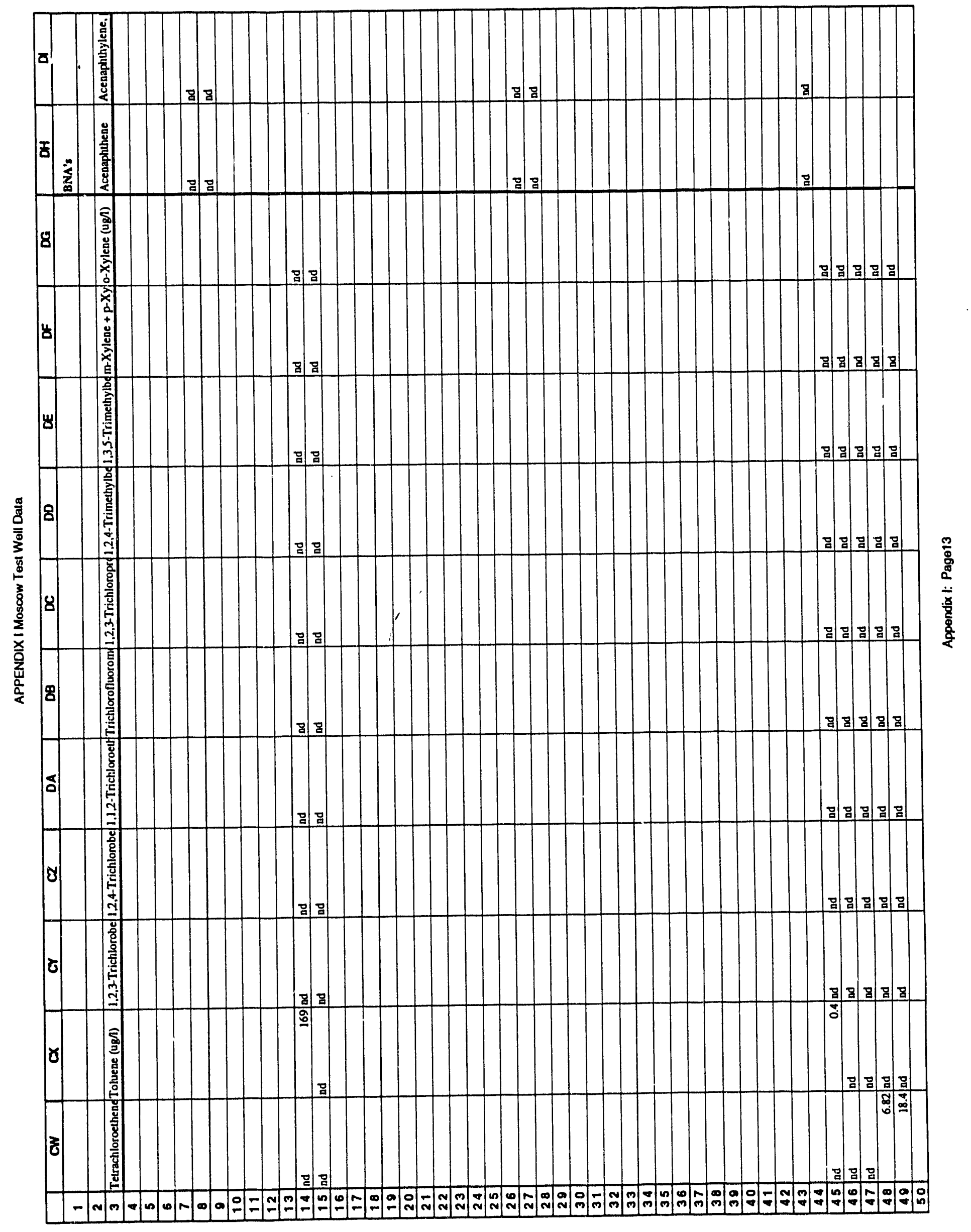




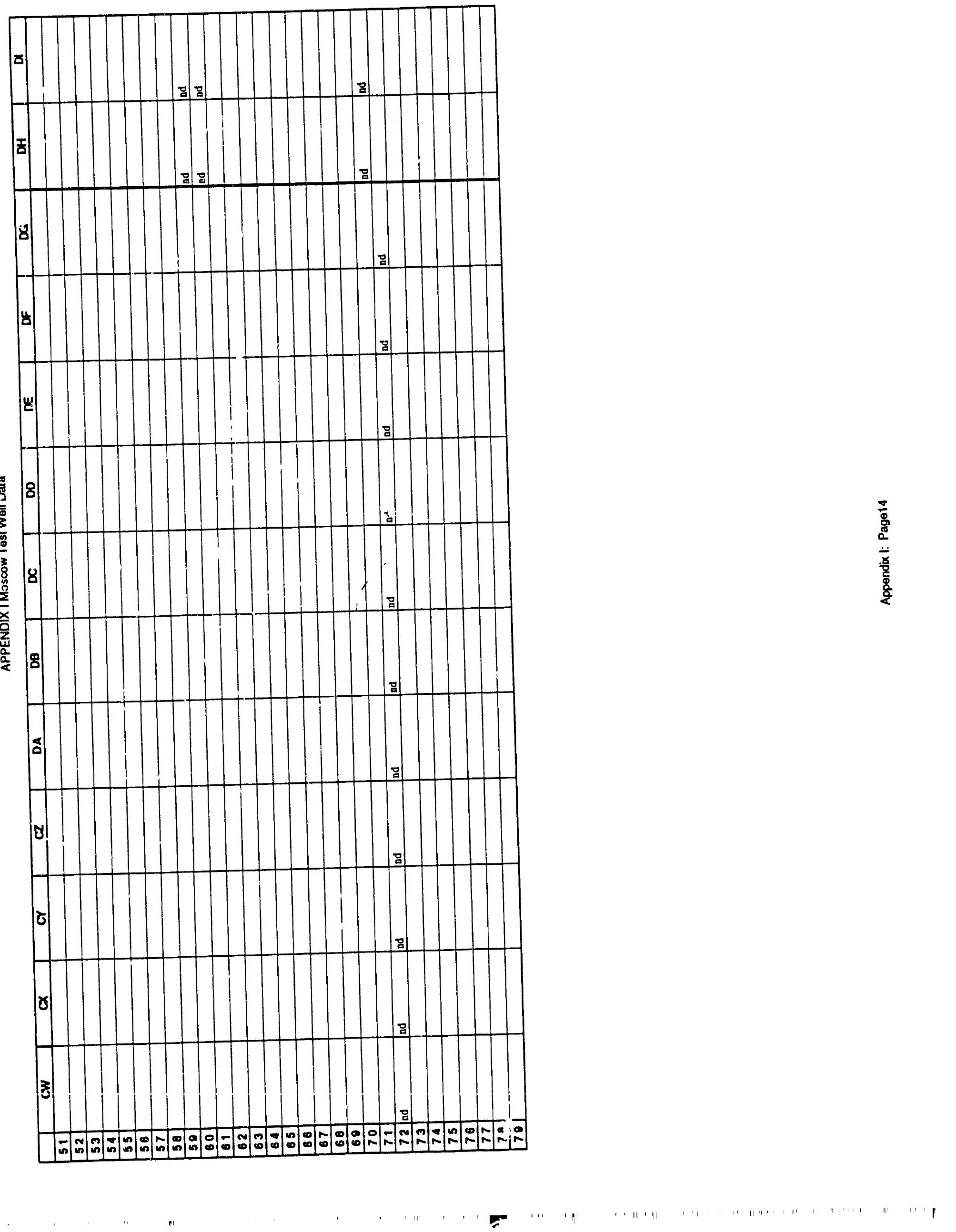




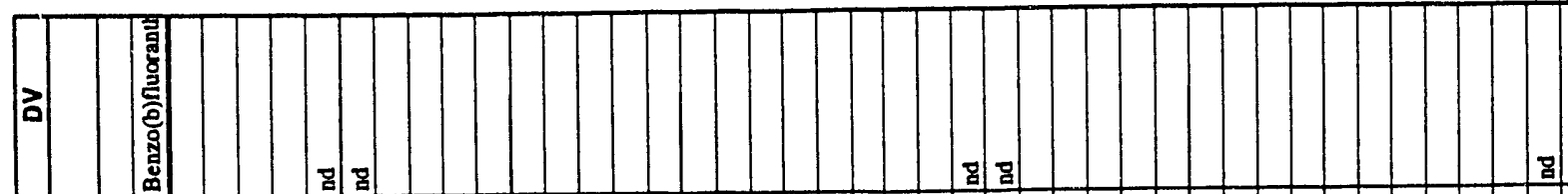

8

:

8

움

:

미믈

믐

ㄴ. $\quad$ 查

:

g:

๖

8 .

감

78

몸

8 8

므

믐

z

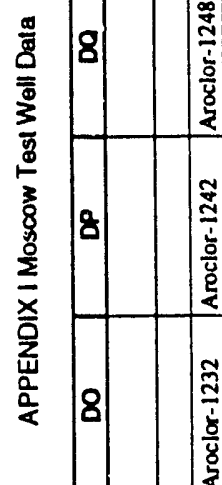

․․

a

$\square$

믈

믐

:

స్

욤

모맘

맘

3 긴

7.

:

음

5

음

$7:$

$\square:$

금

b)

몽

맘

各 递

徥

3

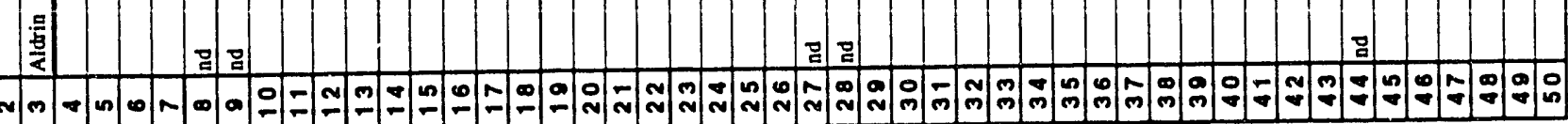




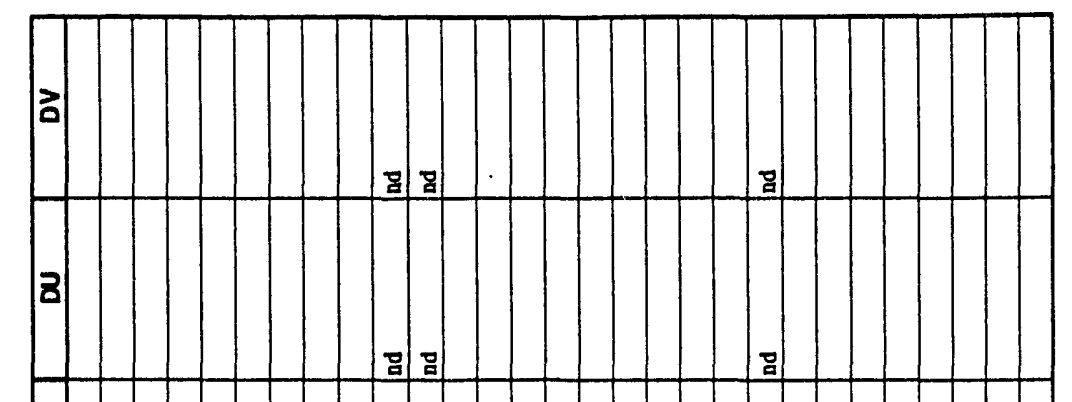

เ

$\Rightarrow$ :

8

맘

7

8

믐

.

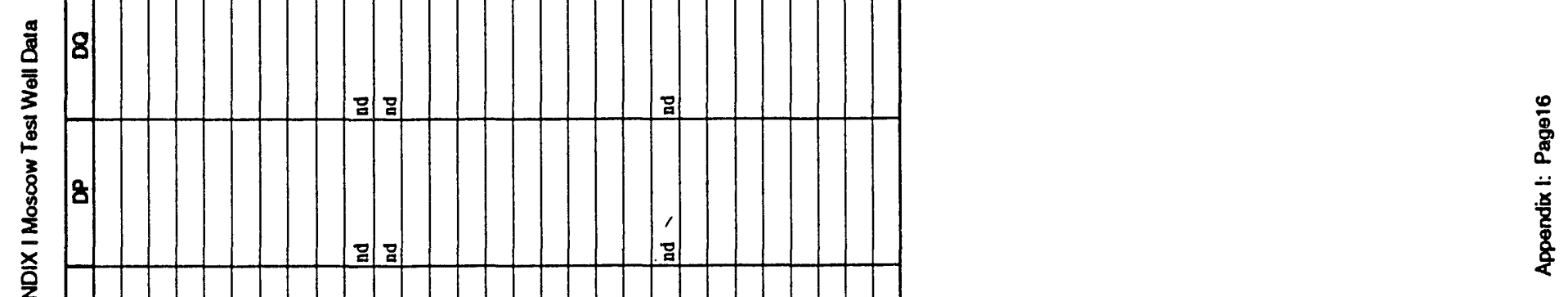

ㄱ:

嵬

子

: :

छ

ᄒ

$\div \div$

a)

5

วั

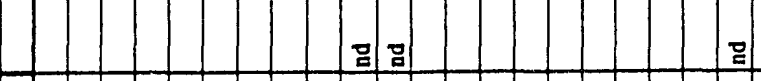

3 


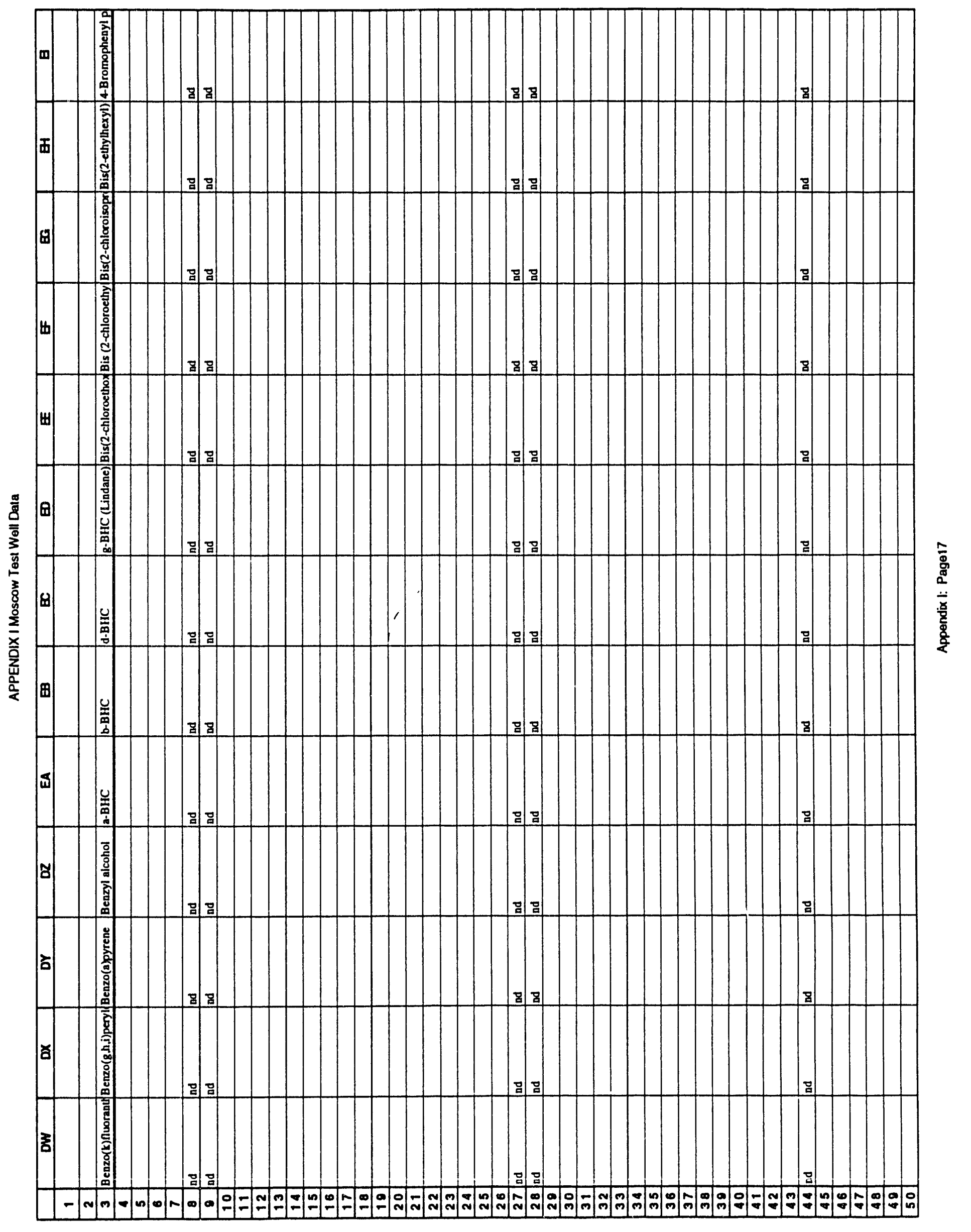




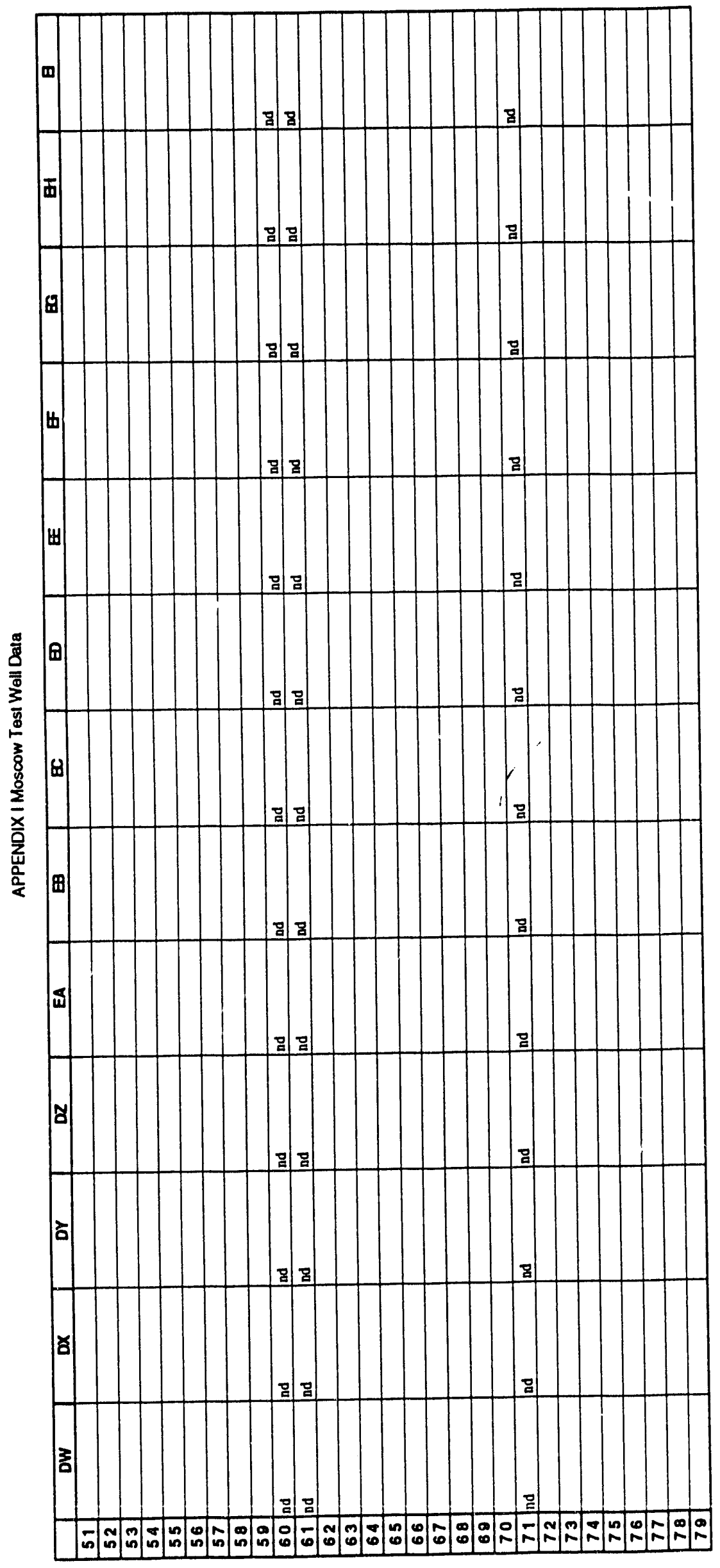


畐

:

밈

g

屯

믐

:

ㅁ

$\infty$

猞

묘 미믐

맘

田

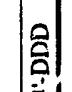

豈

․

ㅁ

:

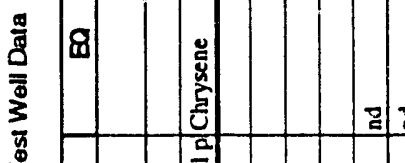

믐

g

믐

:

맘

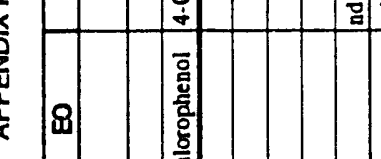

$z$

음

호

\begin{tabular}{|l|l}
\hline \\
\hline
\end{tabular}




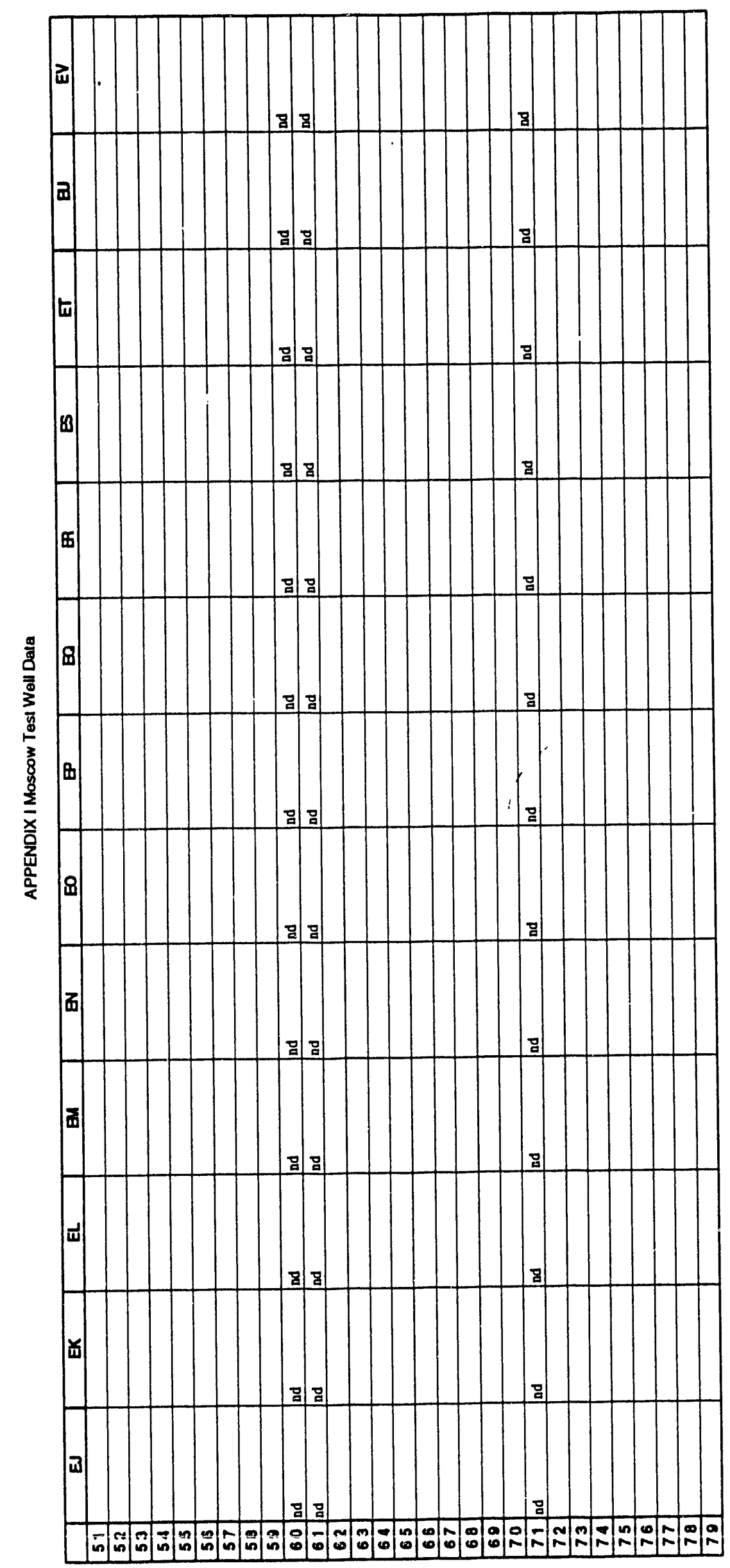




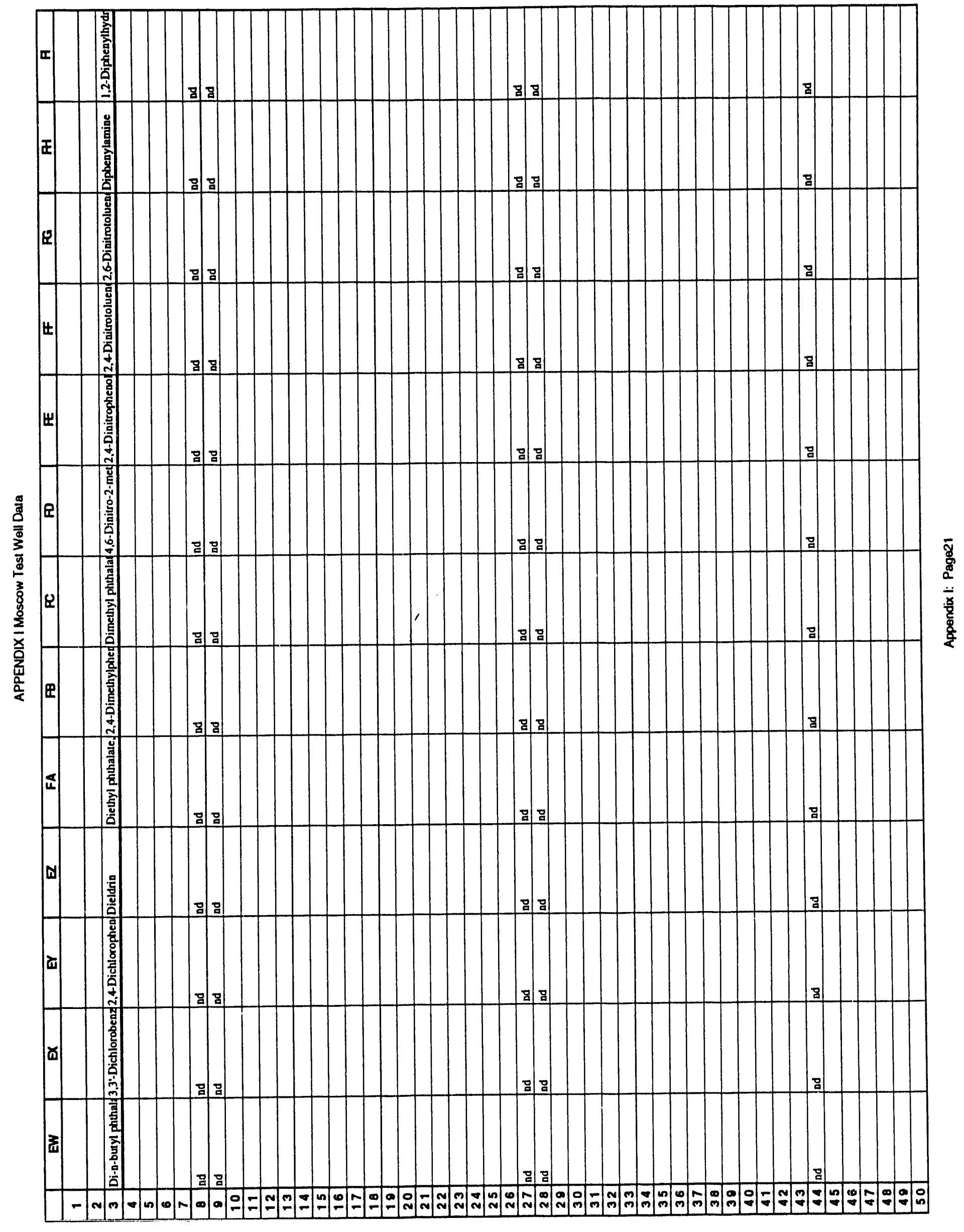




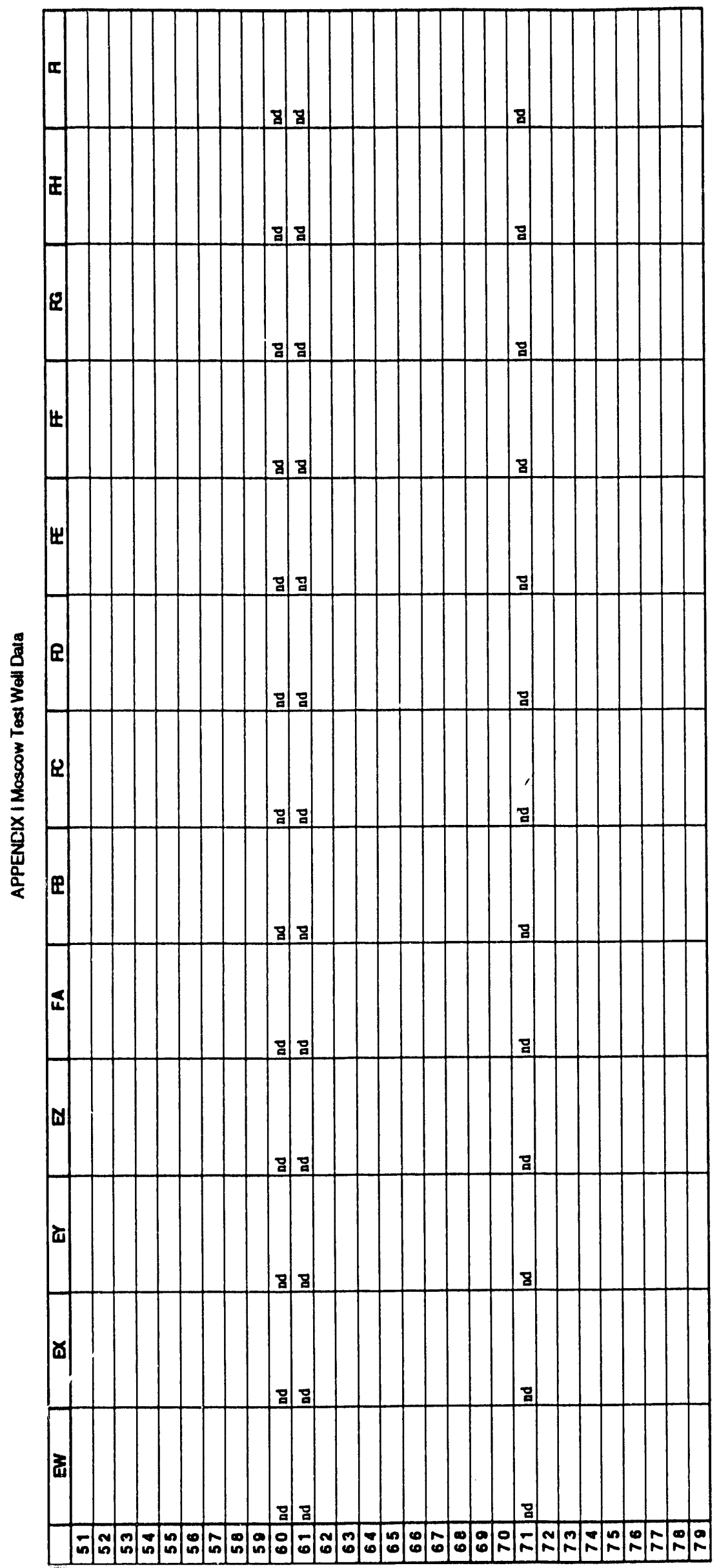




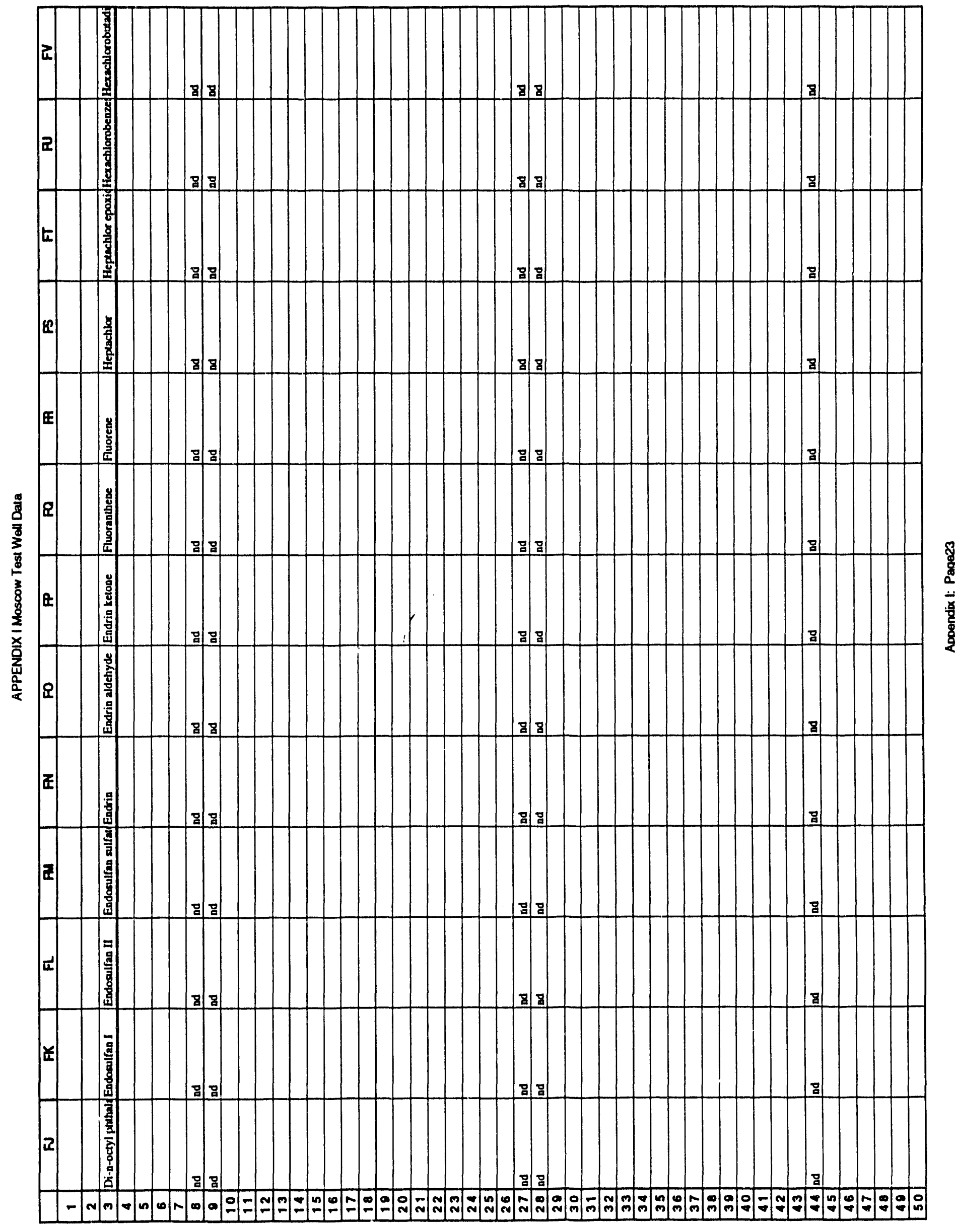




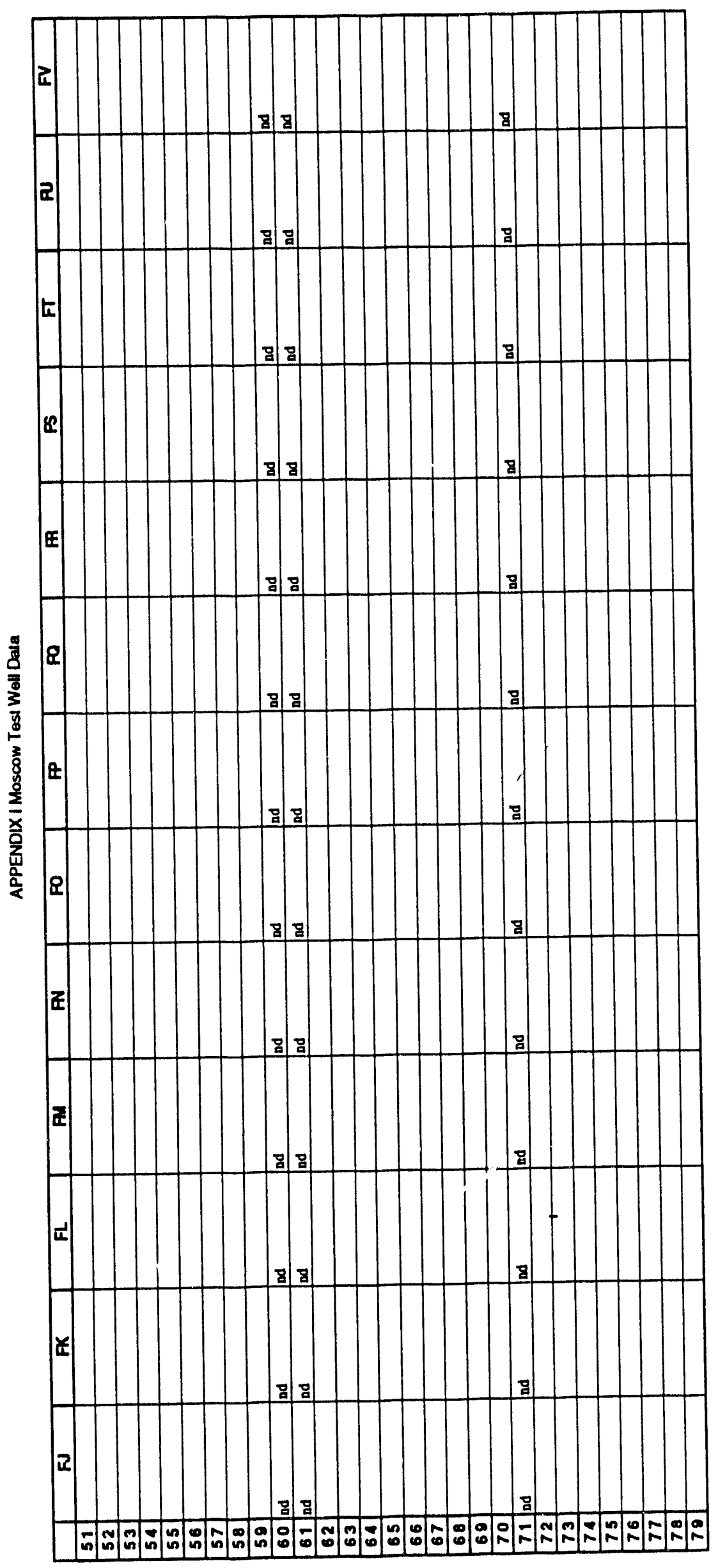




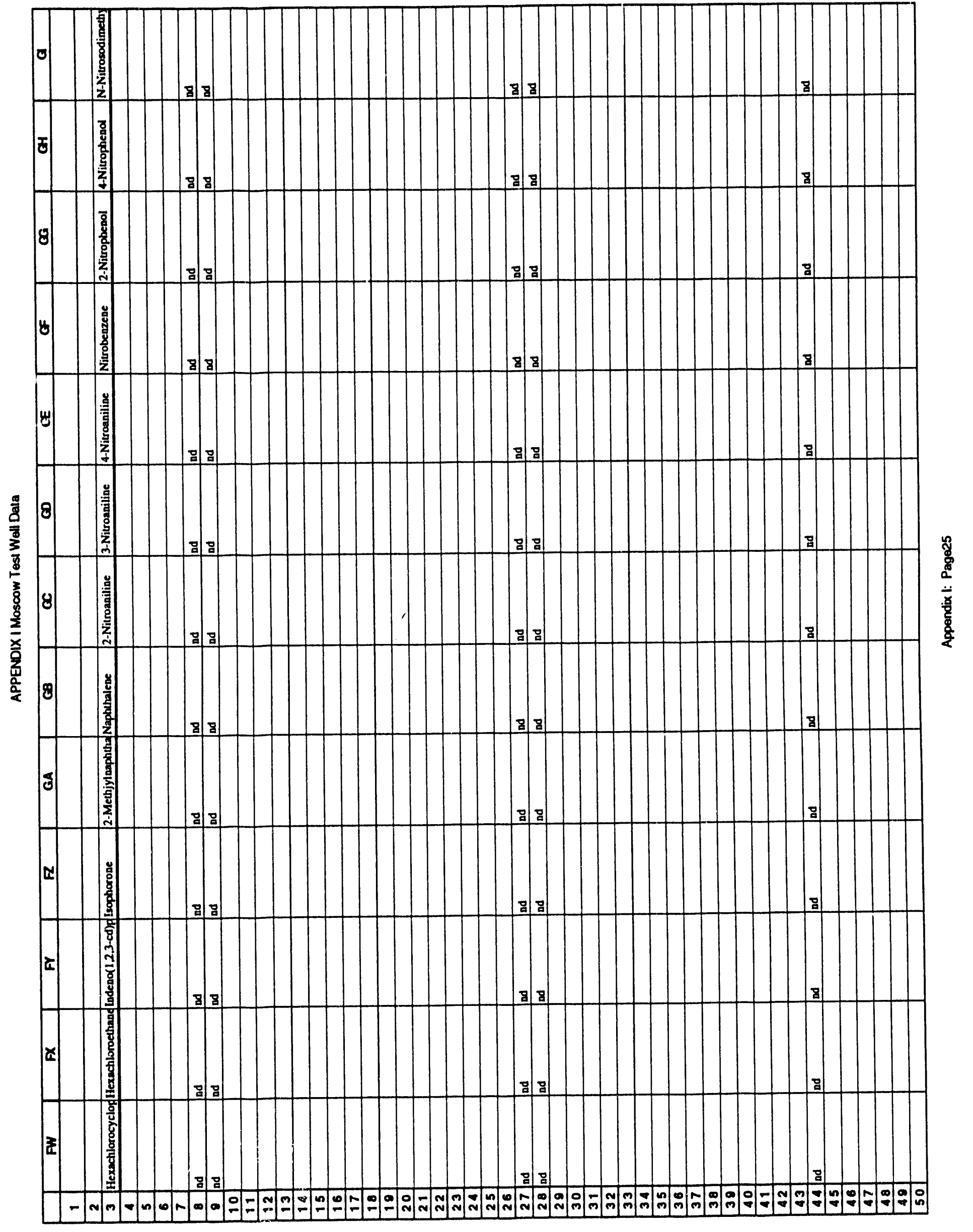




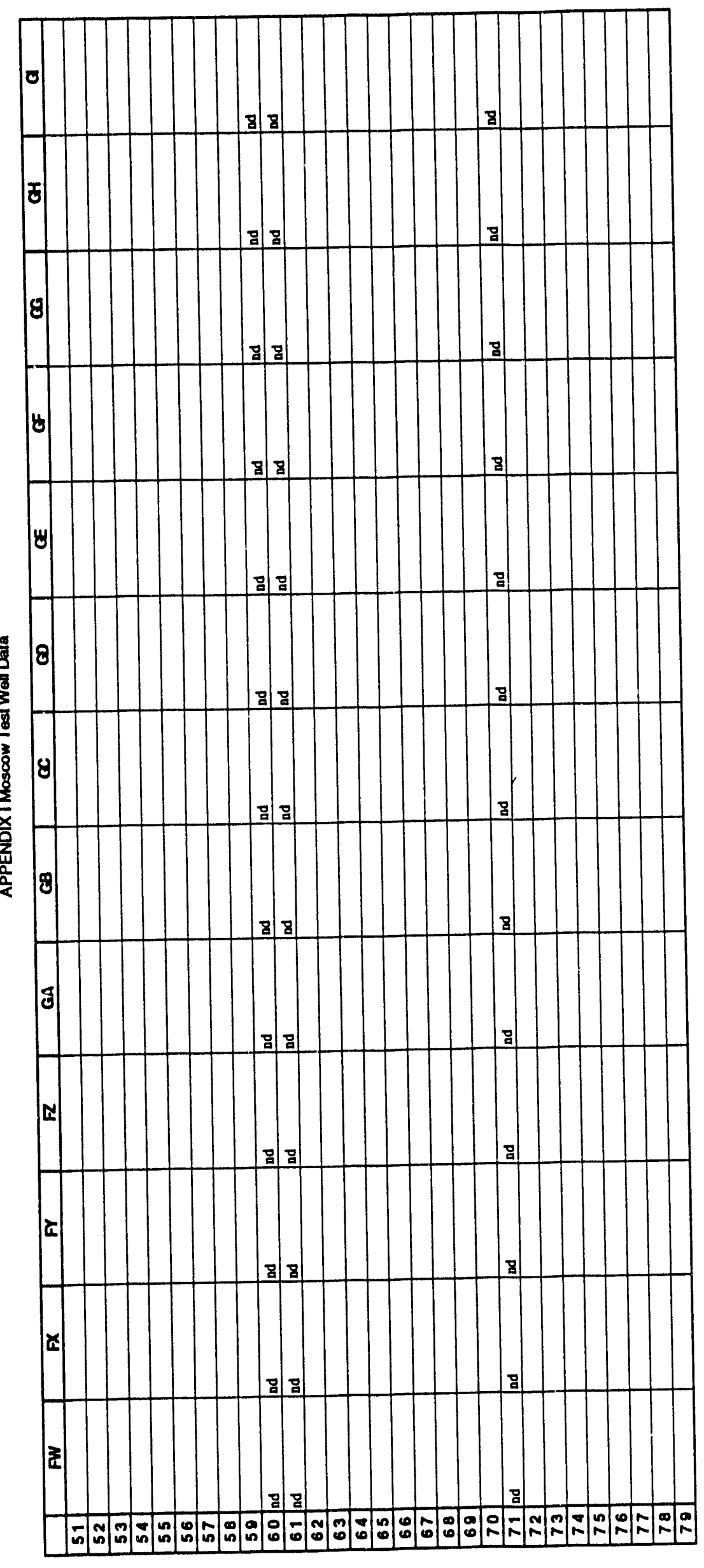




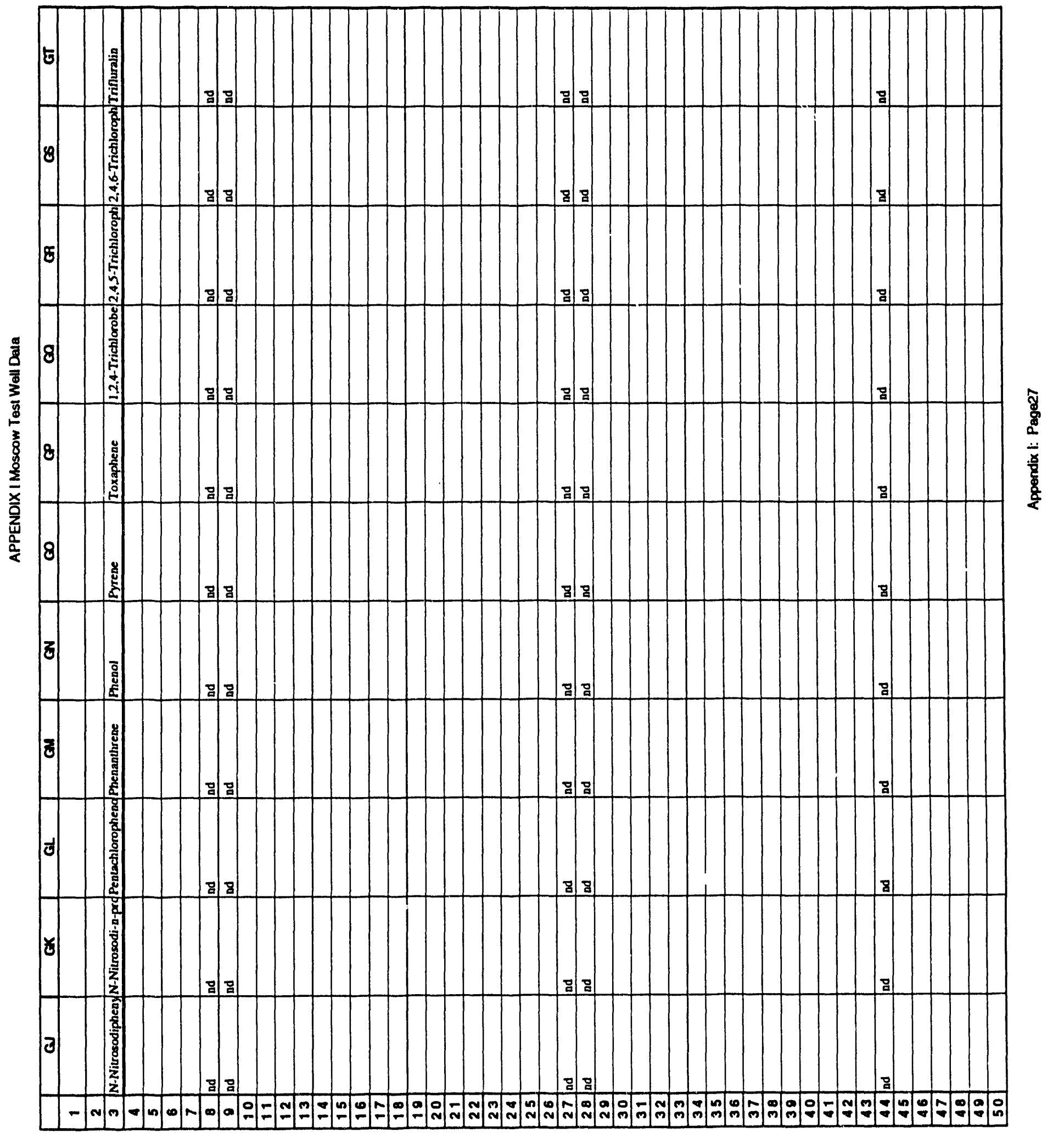




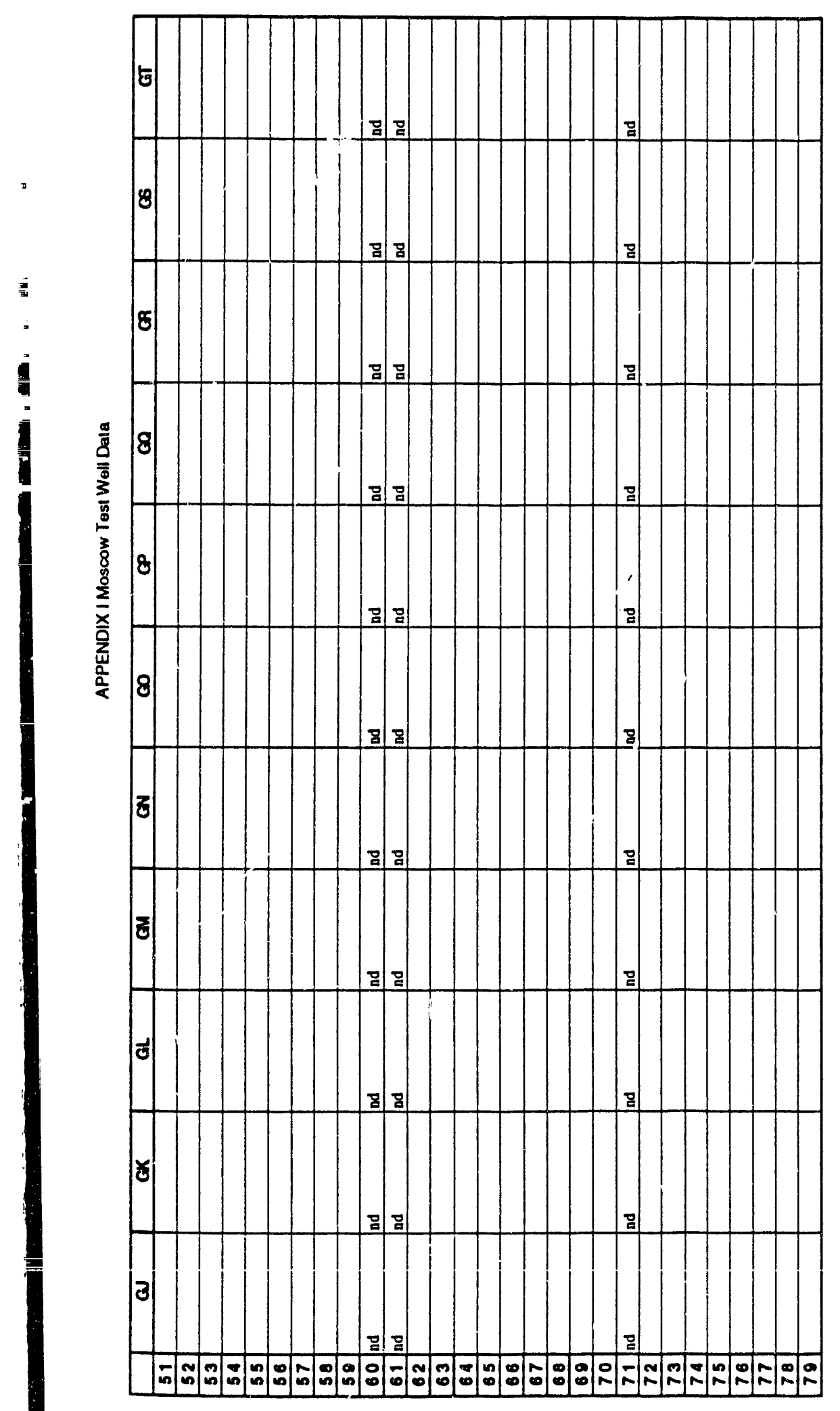



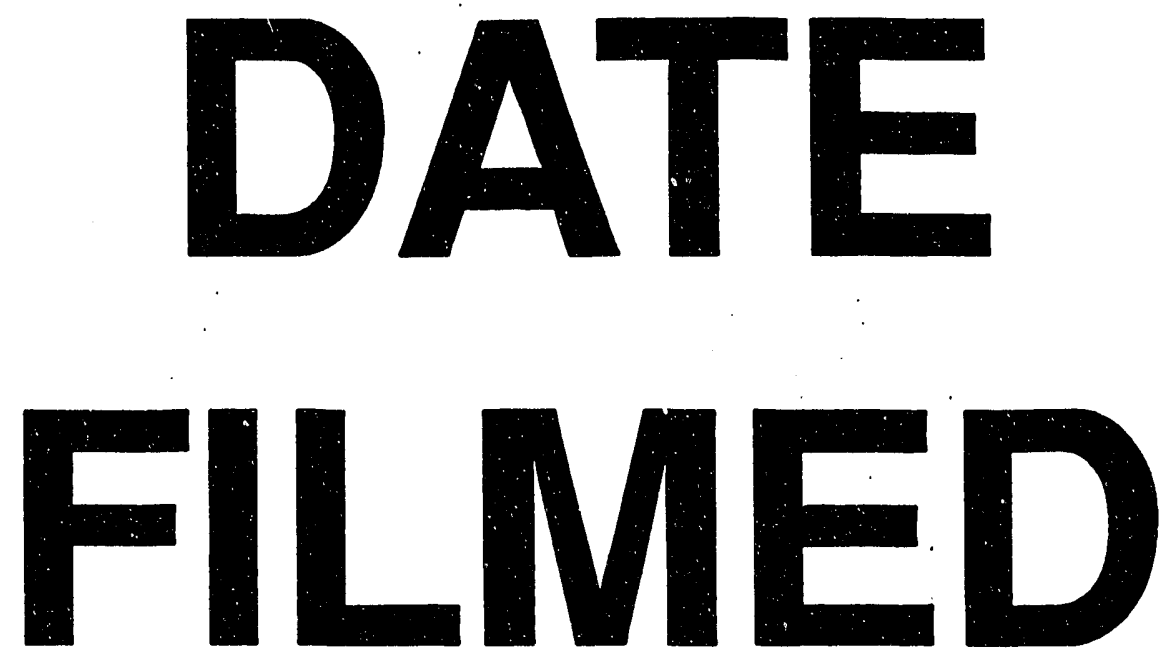

$8 / 17 / 93$
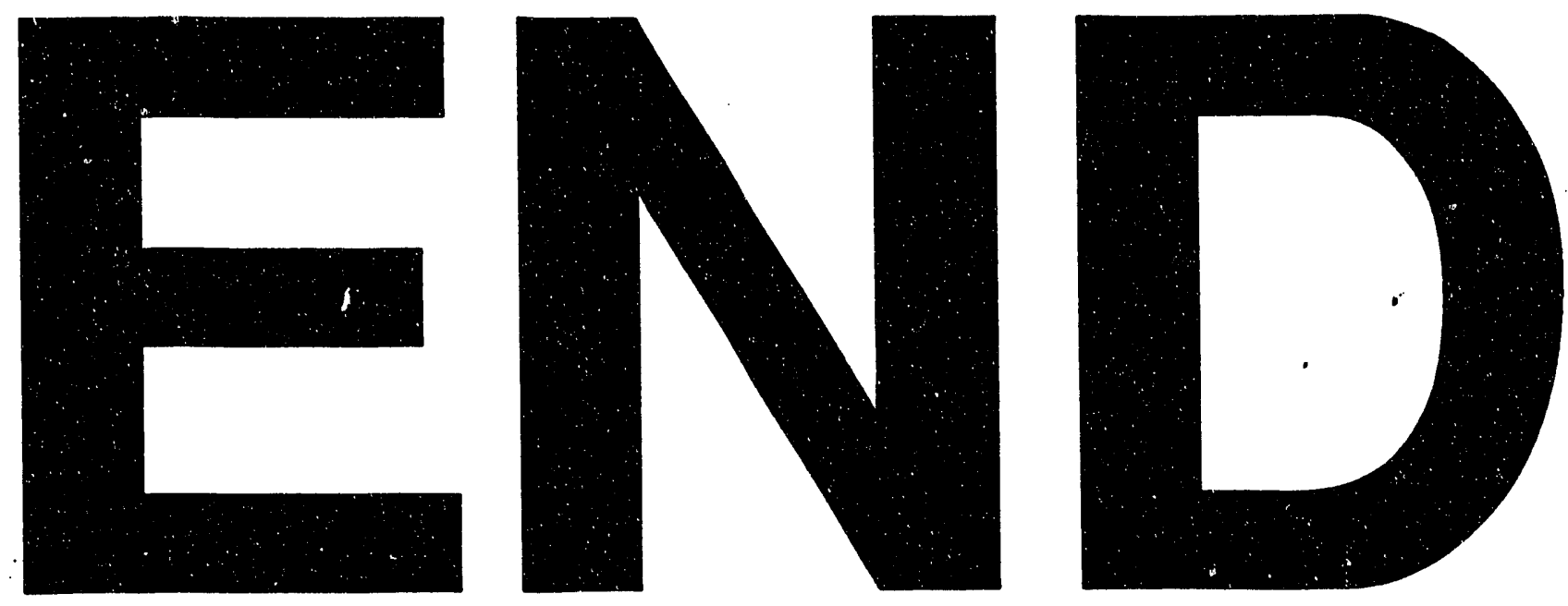


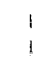

